\title{
Recent trends in aerosol optical properties derived from AERONET measurements
}

\author{
J. Li ${ }^{1,2}$, B. E. Carlson ${ }^{1}$, O. Dubovik ${ }^{3}$, and A. A. Lacis ${ }^{1}$ \\ ${ }^{1}$ Goddard Institute for Space Studies, New York, USA \\ ${ }^{2}$ Department of Applied Physics and Applied Math, Columbia University, New York, USA \\ ${ }^{3}$ French National Center for Scientific Research, University Lille 1, Lille, France
}

Correspondence to: J. Li (jing.li@nasa.gov)

Received: 14 March 2014 - Published in Atmos. Chem. Phys. Discuss.: 3 June 2014

Revised: 6 September 2014 - Accepted: 23 September 2014 - Published: 21 November 2014

\begin{abstract}
The Aerosol Robotic Network (AERONET) has been providing high-quality retrievals of aerosol optical properties from the surface at worldwide locations for more than a decade. Many sites have continuous and consistent records for more than 10 years, which enables the investigation of long-term trends in aerosol properties at these locations. In this study, we present the results of a trend analysis at selected stations with long data records. In addition to commonly studied parameters such as aerosol optical depth (AOD) and Ångström exponent (AE), we also focus on inversion products including absorption aerosol optical depth (ABS), single-scattering albedo (SSA) and the absorption Ångström exponent (AAE). Level 2.0 quality assured data are the primary source. However, due to the scarcity of level 2.0 inversion products resulting from the strict AOD quality control threshold, we have also analyzed level 1.5 data, with some quality control screening to provide a reference for global results. Two statistical methods are used to detect and estimate the trend: the Mann-Kendall test associated with Sen's slope and linear least-squares fitting. The results of these statistical tests agree well in terms of the significance of the trend for the majority of the cases. The results indicate that Europe and North America experienced a uniform decrease in AOD, while significant ( $>90 \%$ ) increases in these two parameters are found for North India and the Arabian Peninsula. The AE trends turn out to be different for North America and Europe, with increases for the former and decreases for the latter, suggesting opposite changes in fine/coarse-mode fraction. For level 2.0 inversion parameters, Beijing and Kanpur both experienced an increase in SSA. Beijing also shows a reduction in ABS, while the SSA
\end{abstract}

increase for Kanpur is mainly due the increase in scattering aerosols. Increased absorption and reduced SSA are found at Solar_Village. At level 1.5, most European and North American sites also show positive SSA and negative ABS trends, although the data are more uncertain. The AAE trends are less spatially coherent due to large uncertainties, except for a robust increase at three sites in West Africa, which suggests a possible reduction in black carbon. Overall, the trends do not exhibit obvious seasonality for the majority of parameters and stations.

\section{Introduction}

Atmospheric aerosols have been recognized as an important climate forcing agent (Charlson et al., 1992) and play a critical role in global climate change (IPCC, 2013). The climate effect of aerosols is determined by their optical properties, including scattering and absorption. Changes in these properties will thus alter the radiative forcing of aerosols. Therefore, understanding the space-time variability of these optical properties is essential in order to quantify the role of aerosol in recent climate variability and climate change. Therefore, long-term trends are of particular interest, because they help us understand the global and regional cycling of different aerosol species of both natural and anthropogenic origin, as well as validate emission inventories and the representation of aerosols in climate models. Aerosol trends are also critical in resolving the change in surface radiation balance over the past few decades, such as global brightening 
found over multiple locations in Europe and North America (Wild et al., 2005; Wild, 2009).

Previously, many studies have investigated long-term trends in aerosol loading and related parameters using satellite or ground-based remote sensing data or in situ measurements. Mishchenko et al. (2007) reported a global decline in aerosol optical depth (AOD) found in AVHRR retrievals since the 1990s. Zhang and Reid (2010) studied regional AOD trends using MODIS and MISR over water product and revealed regional differences in the trends. Xia (2011) analyzed AOD trends using Aerosol Robotic Network (AERONET) data at 79 locations and found significant decreases over North America and Europe. Other studies have analyzed trends in visibility as an aerosol proxy (e.g., Mahowald et al., 2007; Wang et al., 2009; Stjern et al., 2011) or inferred aerosol trends from solar radiation (e.g., Wild, 2009, 2012). Most of the above studies focused on the primary aerosol loading indicator - the optical depth. A few also included the Ångström exponent (AE). However, the trends in other aerosol properties, particularly aerosol absorption, scattering and single-scattering albedo, remain less well known, which is partly attributed to the difficulty in retrieving these variables using remote sensing techniques. Yet aerosol absorption and single-scattering albedo are equally or even more important in determining aerosol forcing. Changes in these quantities impact heavily on both aerosol direct effect and aerosol-cloud interaction. Recently, Collaud Coen et al. (2013) analyzed long-term trends in aerosol scattering and absorption coefficients using in situ measurements at US and European locations. Their study indicated significant reduction in scattering coefficients for both the US and Europe, with less significant reduction in absorption coefficients. These results both improve our understanding of changes in aerosol optical properties and provide an assessment of emission reduction policies. Atmosphere inversion products from AERONET (Holben et al., 1998; Dubovik and King, 2000; Dubovik et al., 2006) involve column retrievals of aerosol scattering and absorption, which complement in situ measurements in providing column optical information. In addition, the AERONET network is much more extensive, covering many important aerosol source regions such as Africa, South America and Asia. As a result, an analysis of long-term trends revealed by AERONET measurements is desirable to better understand the recent changes in aerosol properties over worldwide locations.

A major difficulty in using AERONET inversion products for trend analysis is the uncertainty of the measurements. The accuracy of the retrievals was analyzed in extensive sensitivity studies by Dubovik et al. (2000). Based on the results of these studies, Dubovik at al. (2002) recommended a set of criteria for selecting the high-quality retrieval of all aerosol parameters, including aerosol absorption. These recommendations were adapted as part of quality assurance criteria applied to produce the quality-assured level 2.0 inversion product (Holben et al., 2006). One of the adapted criteria excludes all cases with AOD $<0.4$, because Dubovik et al. (2000) indicated a significant decrease in accuracy of retrieved aerosol parameters with decreasing aerosol optical thickness. For example, the accuracy of the single-scattering albedo (SSA) retrieval dropped from 0.03 to $0.05-0.07$ for AOD values of 0.2 and less. However, the observations with AOD $<0.4$ actually represent the bulk of the data for many stations. As a consequence of this AOD screening, very few stations have longterm, consistent level 2.0 inversion products available. Since there is no other data set with comparable accuracy and coverage, we have therefore also included level 1.5 data for the SSA, absorption aerosol optical depth (ABS) and absorption Ångström exponent (AAE) parameters using the AERONET quality screening, except for the AOD threshold, to provide a reference global result. Moreover, due to gaps in many data records and the non-normal distribution of some parameters (AOD and ABS), caution must be taken when using statistical methods to estimate the magnitude and significance of trends.

In this study, we focus on AERONET level 2.0 AOD and AE retrievals from 90 stations and level 2.0 inversion products from 7 stations. Level 1.5 inversion data at 44 additional stations are also analyzed. Two statistical methods, namely the Mann-Kendall test and linear least-squares fitting, are used to detect the trends in order to improve the robustness of the results.

The paper is organized as follows: Sect. 2 introduces the AERONET data and describes data selection/quality control criteria. Section 3 introduces the analysis techniques with some examples. Section 4 presents the trends for the five parameters in three subsections: level 2.0 AOD and AE; level 2.0 SSA, ABS and AAE; and level 1.5 SSA, ABS and AAE. Discussion of the results is provided in Sect. 5, followed by a summary of the major findings in Sect. 6 .

\section{AERONET data}

The Aerosol Robotic Network (Holben et al., 1998) provides high-quality measurements of major key aerosol optical parameters at over 400 stations globally. The direct solar radiation is used to calculate columnar AOD at \pm 0.01 accuracy for the visible channels. Direct and diffuse measurements can also be inverted to retrieve other properties, including SSA and ABS (Dubovik and King, 2000; Dubovik et al., 2006). The AOD, ABS and SSA used in the trend analysis are at $440 \mathrm{~nm}$. The AE and AAE parameters are from the standard AERONET product, which are derived using AOD and ABS measurements at all four wavelengths in the $[440,870] \mathrm{nm}$ interval, respectively, to provide information on aerosol size and composition. The data are obtained from the version 2 level 2.0 direct measurements for AOD and AE, and level 2.0 and level 1.5 inversion products for the other parameters.

For the purpose of our long-term trend study, we select stations purely based on the availability of an extensive data 


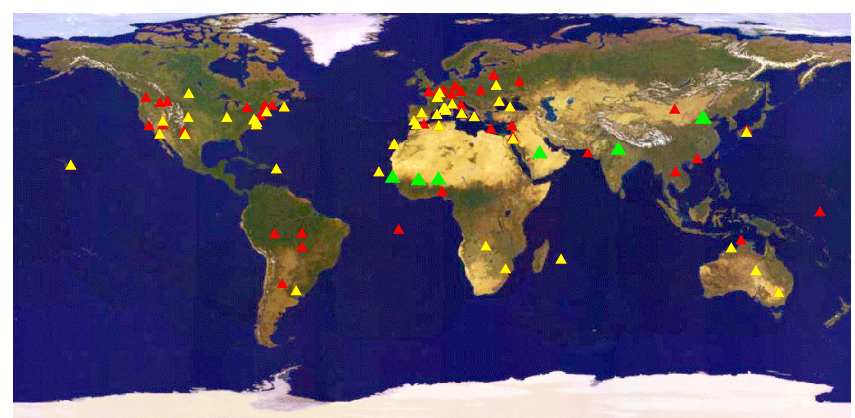

Figure 1. Locations of the stations selected for this study.

record. Specifically, we first calculate monthly medians of the parameters using all-point measurements. The reason for using the median instead of the mean is that many optical parameters such as AOD and ABS do not follow a normal distribution, in which case the median is a better representation than the mean. A monthly median is considered valid only if there are more than five measurements for that month. To ensure a continuous time series, we require the data record to have at least 6 years of measurements, with no less than nine monthly data points for each year during the 2000 to 2013 period. For the direct sun measurement, 90 stations are selected. For the inversion product, only seven stations have qualified level 2.0 data, and they are mostly located in heavily polluted regions in the Northern Hemisphere. The level 2.0 quality assurance for the inversion product enforces several thresholds. In particular, only measurements made at solar zenith angle $>50^{\circ}$, sky error $<5 \%$ and $440 \mathrm{~nm} \mathrm{AOD}>0.4$ are considered accurate (Holben et al., 2006). However, the AOD threshold excludes the majority of the stations, especially those located in North America, Europe and the Southern Hemisphere, where AOD is usually low. For a preliminary examination of changes in aerosol absorption properties worldwide, which is still limited in the literature, we make use of level 1.5 data with some screening. Specifically, the solar zenith angle and sky error requirements are applied to all-point level 1.5 measurements, but not the AOD threshold. Also, we only select level 1.5 data when there were coincident (within $\sim 1 \mathrm{~min}$ ) level 2.0 AOD data available. This ensures the accuracy of input sky radiances. Forty-four level 1.5 stations are then selected, covering most of North America, Europe and some places in the Southern Hemisphere. The locations and number of available monthly medians used for the analysis are listed in Table 1 (AOD and AE) and Table 2 (SSA, ABS and AAE). The distributions of the stations are displayed Fig. 1. All stations in Fig. 1 are used for AOD and $\mathrm{AE}$ analysis, the stations marked in green are also used for level 2.0 SSA, ABS and AAE analysis, and those marked in yellow are used for level 1.5 analysis.

\section{Trend analysis methods}

Detecting trends in time series data is a non-trivial task, especially when many of the parameters are not normally distributed and autocorrelation associated with seasonality usually exists in the record. To determine and estimate annual trends, a two-step approach is used here. First, we apply a 12-month running mean to the deseasonalized data (by removing multi-year averaged seasonal cycle) to manually observe the underlying smoothed structure. Next, two statistical methods - the seasonal Mann-Kendall (MK) test associated with Sen's slope and linear least-squares fitting of the deseasonalized data - are used to further test and estimate the trends. Moreover, we also estimate the trend using the MK and least-squares methods for each season in order to examine whether there is obvious seasonality in the trends. The two trend analysis techniques are described in the following two subsections.

\subsection{Mann-Kendall test and Sen's slope}

The Mann-Kendall statistical test (Mann, 1945; Kendall, 1975 ) is a nonparametric test to identify whether monotonic trends exist in a time series. The advantage of the nonparametric statistical tests over the parametric tests, such as the $t$ test, is that the nonparametric tests are more suitable for nonnormally distributed, censored and missing data, which are frequently encountered in the AERONET data record. However, many time series of aerosol parameters may frequently display statistically significant serial correlation, especially those associated with seasonal variability. In such cases, the existence of serial correlation will increase the probability that the MK test detects a significant trend (von Storch, 1995; Yue et al., 2002; Zhang and Zwiers, 2004). It is therefore necessary to "pre-whiten" the time series by eliminating the influence of AR(1) serial correlation before performing the test. Yue et al. (2002) indicate that directly removing the $\mathrm{AR}(1)$ component from the raw time series also removes part of the magnitude of the trend and proposed a pre-whitening scheme by first removing the linear trend from the time series using

$X_{t}^{\prime}=X_{t}-T=X_{t}-b t$,

where $b$ is the slope of the trend estimated using Sen's method (Sen, 1968), and then removing the AR(1) component from $X_{t}^{\prime}$ using

$Y_{t}^{\prime}=X_{t}^{\prime}-r_{1} X_{t-1}^{\prime}$,

where $r_{1}$ is lag-1 autocorrelation, and finally adding the trend back using

$Y_{t}=Y_{t}^{\prime}+T_{t}$.

The blended time series $Y$ preserves the true trend but is no longer influenced by the effect of autocorrelation. Furthermore, Hirsch et al. $(1982,1984)$ extended the MK test 
Table 1. Location, aerosol type, number of months used in the analysis $(N)$, and trends (decade) for $440 \mathrm{~nm}$ AOD and AE at the 90 selected stations. Bold values indicate trends at $90 \%$ significance level. For least-squares fitting, as the logarithm of some parameters are used, the trends are only indicated by positive or negative.

\begin{tabular}{|c|c|c|c|c|c|c|c|c|}
\hline & \multirow[t]{2}{*}{ Station } & \multirow[t]{2}{*}{ Longitude } & \multirow[t]{2}{*}{ Latitude } & \multirow[t]{2}{*}{$N$} & \multicolumn{2}{|c|}{ Mann-Kendall } & \multicolumn{2}{|c|}{ Least-squares fitting } \\
\hline & & & & & AOD & $\mathrm{AE}$ & AOD & $\mathrm{AE}$ \\
\hline \multirow{24}{*}{ 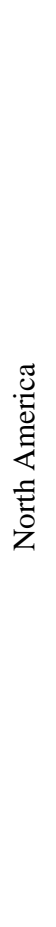 } & BONDVILLE & -88.4 & 40.1 & 132 & -0.03 & 0.3 & Negative & Positive \\
\hline & BSRN_BAO_Boulder & -105.0 & 40.0 & 123 & -0.01 & -0.2 & Negative & Negative \\
\hline & Billerica & -71.3 & 42.5 & 107 & 0.01 & 0.16 & Positive & Positive \\
\hline & Bratts_Lake & -104.7 & 50.3 & 142 & 0.01 & -0.54 & Positive & Negative \\
\hline & CARTEL & -71.9 & 45.4 & 124 & 0.01 & 0.21 & Positive & Positive \\
\hline & CCNY & -73.9 & 40.8 & 117 & -0.01 & -0.04 & Negative & Negative \\
\hline & COVE & -75.7 & 36.9 & 93 & -0.01 & 0.05 & Negative & Positive \\
\hline & Egbert & -79.8 & 44.2 & 134 & -0.01 & -0.14 & Negative & Negative \\
\hline & French_Flat & -115.9 & 36.8 & 70 & -0.03 & 0.51 & Negative & Positive \\
\hline & GSFC & -76.8 & 40.0 & 166 & -0.01 & -0.04 & Negative & Negative \\
\hline & Halifax & -63.6 & 44.6 & 110 & -0.01 & -0.21 & Positive & Negative \\
\hline & Harvard_Forest & -72.2 & 42.5 & 86 & -0.04 & -0.13 & Negative & Negative \\
\hline & Howland & -68.7 & 45.2 & 88 & -0.01 & 0.17 & Negative & Positive \\
\hline & La_Jolla & -117.3 & 32.9 & 103 & -0.03 & -0.14 & Negative & Negative \\
\hline & MD_Science_Center & -76.6 & 39.3 & 149 & 0.00 & -0.10 & Positive & Negative \\
\hline & Missoula & -114.1 & 46.9 & 123 & 0.00 & 0.20 & Positive & Positive \\
\hline & Monterey & -121.9 & 36.6 & 80 & -0.01 & -0.07 & Negative & Negative \\
\hline & Railroad_Valley & -116.0 & 38.5 & 97 & -0.00 & 0.18 & Negative & Positive \\
\hline & Rimrock & -117.0 & 46.5 & 140 & 0.00 & 0.12 & Positive & Positive \\
\hline & SERC & -76.5 & 38.9 & 114 & 0.00 & 0.09 & Positive & Positive \\
\hline & Saturn_Island & -123.1 & 48.8 & 129 & 0.02 & 0.11 & Positive & Positive \\
\hline & Sevilleta & -106.9 & 34.4 & 121 & -0.01 & 0.05 & Negative & Positive \\
\hline & Wallops & -75.5 & 37.9 & 129 & 0.01 & -0.03 & Positive & Negative \\
\hline & White_Sands_HELSTF & -106.3 & 32.6 & 83 & 0.02 & 0.01 & Positive & Positive \\
\hline \multirow{6}{*}{ 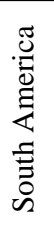 } & Alta_Floresta & -56.1 & -9.9 & 148 & -0.01 & -0.14 & Negative & Negative \\
\hline & CEILAP-BA & -58.5 & -34.6 & 99 & 0.0 & -0.05 & Positive & Negative \\
\hline & Cordoba-CETT & -64.5 & -31.5 & 76 & 0.01 & 0.23 & Positive & Positive \\
\hline & CUIABA-MIRANDA & -56.0 & -15.7 & 107 & -0.08 & -0.18 & Negative & Negative \\
\hline & La_Parguera & -67.0 & 18.0 & 132 & -0.01 & 0.04 & Negative & Positive \\
\hline & Rio_Branco & -67.9 & -10.0 & 95 & -0.00 & -0.11 & Negative & Negative \\
\hline \multirow{18}{*}{$\begin{array}{l}\stackrel{0}{0} \\
\stackrel{0}{0} \\
\stackrel{10}{\infty} \\
.\end{array}$} & Avignon & 4.9 & 43.9 & 143 & -0.02 & -0.05 & Negative & Negative \\
\hline & Barcelona & 2.1 & 41.4 & 100 & -0.07 & -0.33 & Negative & Negative \\
\hline & Belsk & 20.8 & 51.8 & 101 & -0.05 & -0.05 & Negative & Negative \\
\hline & Cabauw & 4.9 & 52.0 & 104 & -0.09 & 0.02 & Negative & Negative \\
\hline & Carpentras & 5.1 & 44.1 & 129 & -0.07 & -0.13 & Negative & Negative \\
\hline & Chilbolton & -1.4 & 51.1 & 90 & -0.02 & -0.06 & Negative & Negative \\
\hline & Dunkerque & 2.4 & 51.0 & 104 & -0.07 & -0.07 & Negative & Negative \\
\hline & El_Arenosillo & -6.7 & 37.1 & 105 & -0.01 & -0.34 & Negative & Negative \\
\hline & Evora & -7.9 & 38.6 & 114 & -0.05 & -0.05 & Negative & Negative \\
\hline & FORTH_CRETE & 25.3 & 35.3 & 101 & -0.01 & -0.14 & Positive & Negative \\
\hline & Granada & -3.6 & 37.2 & 82 & -0.03 & -0.31 & Negative & Negative \\
\hline & Hamburg & 10.0 & 53.6 & 99 & 0.04 & -0.50 & Positive & Negative \\
\hline & IFT-Leipzig & 12.4 & 51.3 & 124 & -0.05 & -0.04 & Negative & Negative \\
\hline & Ispra & 8.6 & 45.8 & 114 & -0.03 & -0.17 & Negative & Negative \\
\hline & IMS-METU-ERDEMLI & 34.3 & 36.6 & 124 & -0.02 & -0.04 & Negative & Negative \\
\hline & Lecce_University & 18.1 & 40.3 & 106 & -0.06 & 0.03 & Negative & Positive \\
\hline & Lille & 3.1 & 50.6 & 161 & -0.04 & -0.03 & Negative & Negative \\
\hline & Mainz & 8.3 & 50.0 & 98 & -0.04 & -0.21 & Negative & Negative \\
\hline
\end{tabular}


Table 1. Continued.

\begin{tabular}{|c|c|c|c|c|c|c|c|c|}
\hline & \multirow[t]{2}{*}{ Station } & \multirow[t]{2}{*}{ Longitude } & \multirow[t]{2}{*}{ Latitude } & \multirow[t]{2}{*}{$N$} & \multicolumn{2}{|c|}{ Mann-Kendall } & \multicolumn{2}{|c|}{ Least-squares fitting } \\
\hline & & & & & AOD & $\mathrm{AE}$ & AOD & $\mathrm{AE}$ \\
\hline & Minsk & 27.6 & 53.9 & 112 & -0.01 & -0.01 & Negative & Negative \\
\hline & Moldova & 28.8 & 47 & 139 & -0.01 & -0.04 & Negative & Negative \\
\hline & Moscow_MSU_MO & 37.5 & 55.7 & 123 & -0.03 & -0.05 & Negative & Negative \\
\hline & OHP_OBSERVATOIRE & 5.7 & 43.9 & 100 & -0.03 & -0.48 & Negative & Negative \\
\hline & Palaiseau & 2.2 & 48.7 & 134 & -0.04 & -0.02 & Negative & Negative \\
\hline & Palencia & -4.5 & 42.0 & 95 & -0.00 & -0.01 & Negative & Positive \\
\hline & Paris & 2.3 & 48.9 & 98 & -0.07 & 0.09 & Negative & Positive \\
\hline & Rome_Tor_Vergata & 12.6 & 41.8 & 135 & -0.03 & 0.06 & Negative & Positive \\
\hline & Sevastopol & 33.5 & 44.6 & 85 & -0.04 & -0.33 & Negative & Negative \\
\hline & Toravere & 26.5 & 58.3 & 108 & -0.04 & -0.08 & Negative & Negative \\
\hline & Toulon & 6.0 & 43.1 & 72 & -0.06 & -0.05 & Negative & Negative \\
\hline & Venise & 12.5 & 45.3 & 75 & -0.04 & -0.18 & Negative & Negative \\
\hline \multirow{12}{*}{$\frac{\pi}{\pi}$} & Beijing & 116.4 & 40.0 & 135 & -0.10 & -0.01 & Negative & Negative \\
\hline & Dalanzadgad & 104.4 & 43.6 & 106 & 0.01 & -0.32 & Positive & Negative \\
\hline & Kanpur & 80.2 & 26.5 & 141 & 0.08 & -0.11 & Positive & Positive \\
\hline & Karachi & 63.1 & 24.9 & 69 & 0.11 & 0.04 & Positive & Positive \\
\hline & Hong_Kong_PolyU & 114.2 & 22.3 & 83 & -0.11 & 0.12 & Negative & Negative \\
\hline & Mukdahan & 104.7 & 16.6 & 70 & -0.06 & -0.17 & Negative & Negative \\
\hline & Nes_Ziona & 34.8 & 31.9 & 125 & -0.01 & -0.24 & Negative & Negative \\
\hline & Osaka & 135.6 & 34.7 & 107 & -0.06 & 0.07 & Negative & Positive \\
\hline & SEDE_BOKER & 34.8 & 30.9 & 156 & 0.00 & 0.01 & Positive & Positive \\
\hline & Shirahama & 135.4 & 33.7 & 127 & -0.03 & 0.06 & Negative & Positive \\
\hline & Solar_Village & 46.4 & 24.9 & 139 & 0.13 & -0.13 & Positive & Negative \\
\hline & XiangHe & 117.0 & 39.8 & 94 & -0.18 & 0.11 & Negative & Positive \\
\hline \multirow{11}{*}{ 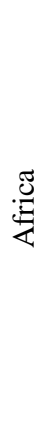 } & Banizoumbou & 2.7 & 13.5 & 148 & -0.02 & -0.07 & Negative & Negative \\
\hline & Capo_Verde & -22.9 & 16.7 & 148 & -0.03 & -0.03 & Negative & Negative \\
\hline & Blida & 2.9 & 36.5 & 86 & -0.07 & -0.02 & Negative & Negative \\
\hline & Dakar & -17.0 & 14.4 & 133 & -0.01 & -0.04 & Negative & Negative \\
\hline & IER_Cinzana & -5.9 & 13.3 & 114 & -0.07 & -0.12 & Negative & Negative \\
\hline & Ilorin & 4.3 & 8.3 & 104 & -0.08 & 0.03 & Negative & Positive \\
\hline & Izana & -16.5 & 28.3 & 103 & 0.01 & 0.08 & Positive & Positive \\
\hline & La_Laguna & -16.3 & 28.5 & 64 & -0.01 & 0.49 & Negative & Positive \\
\hline & Mongu & 23.2 & -15.3 & 99 & 0.00 & 0.18 & Positive & Positive \\
\hline & Santa_Cruz_Tenerife & -16.2 & 28.5 & 86 & -0.03 & -0.21 & Negative & Negative \\
\hline & Skukuza & 31.6 & -25.0 & 126 & 0.02 & 0.06 & Positive & Positive \\
\hline \multirow{3}{*}{ 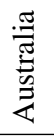 } & Canberra & 149.1 & -35.3 & 125 & 0.00 & -0.03 & Positive & Negative \\
\hline & Jabiru & 132.9 & -12.7 & 107 & 0.00 & 0.09 & Positive & Positive \\
\hline & Lake_Argyle & 128.7 & -16.1 & 124 & 0.01 & 0.12 & Positive & Positive \\
\hline \multirow{4}{*}{$\begin{array}{l}\frac{\mathscr{a}}{\Xi} \\
\frac{\vec{\Xi}}{\Omega}\end{array}$} & AscensionIsland & -14.42 & -7.98 & 102 & 0.00 & 0.12 & Positive & Positive \\
\hline & Mauna_Loa & -155.6 & 19.5 & 172 & 0.00 & -0.01 & Positive & Negative \\
\hline & Nauru & 166.9 & -0.52 & 82 & 0.02 & -0.19 & Positive & Negative \\
\hline & REUNION_ST_DENIS & 55.5 & -20.9 & 77 & 0.02 & -0.47 & Positive & Negative \\
\hline
\end{tabular}

to take seasonality into account, and estimated annual trend as the median of seasonal trends. Here we adopt the Yue et al. (2002) pre-whitening scheme and perform the seasonal MK test on the pre-whitened times series $Y$. Two-tailed tests at both 95 and $90 \%$ significance level were applied to test either an upward or downward trend.
To estimate the true slope $b$ of the trend, we use the nonparametric procedure developed by Sen (1968) as follows:

$b=\operatorname{Median}\left(\frac{X_{i}-X_{j}}{i-j}\right) \forall j<i$.

A $90 \%$ significance level is applied to calculate the upper and lower limits of the confidence interval of the slope. 
Table 2. Location, aerosol type, number of months used in the analysis $(N)$, and trends (decade) for $440 \mathrm{~nm}$ SSA, ABS and AAE at the 54 selected stations. Bold values indicate trends at $90 \%$ significance level. For least-squares fitting, as the logarithm of some parameters are used, the trends are only indicated by positive or negative.

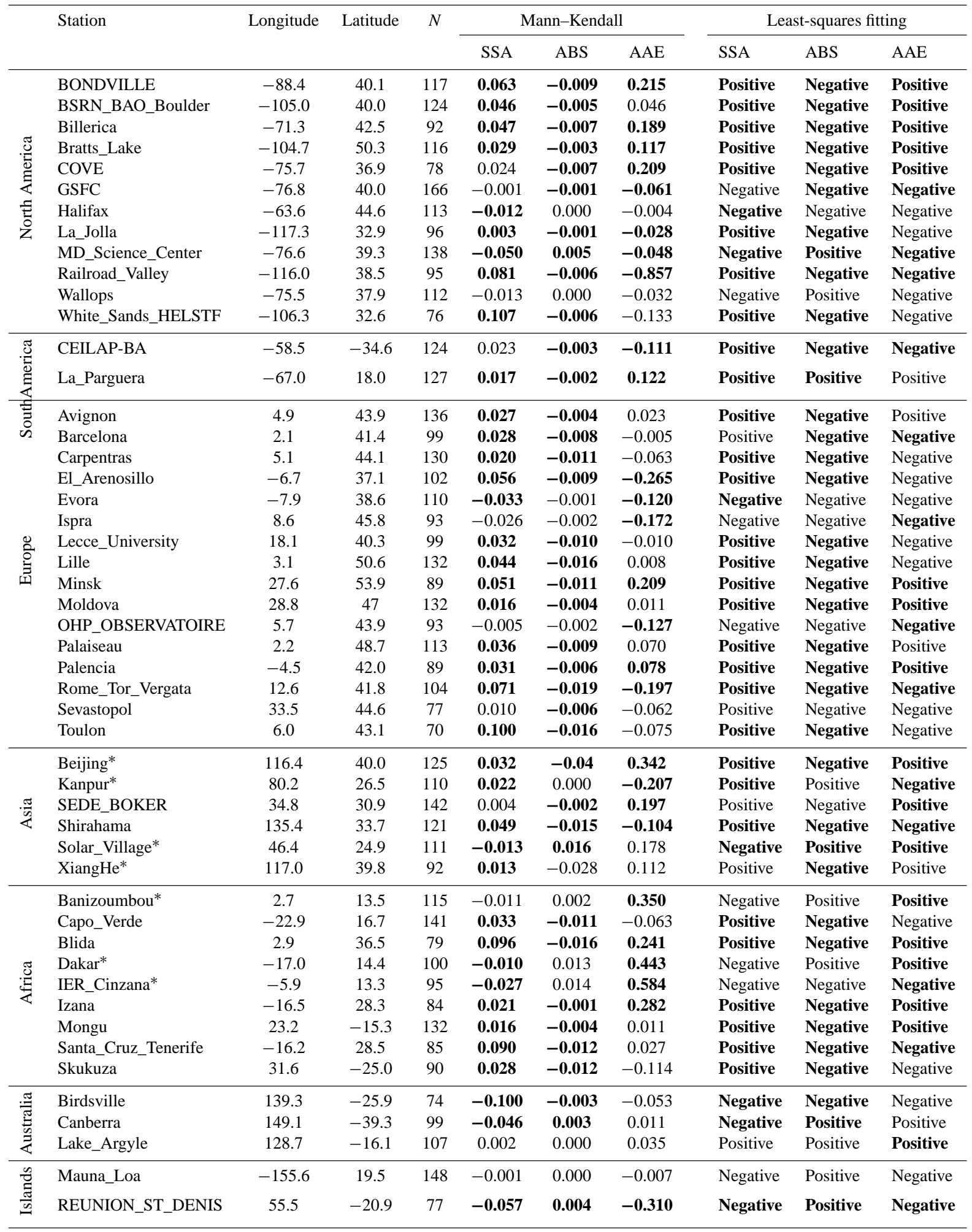


Compared to other slope estimators such as the linear regression coefficient, Sen's slope is much less sensitive to outliers, which is particularly suitable for level 1.5 data, in which outliers occasionally appear.

\subsection{Linear least-squares fitting}

Linear trends and their significance level are also estimated using the method by Weatherhead et al. (1998). The data time series is modeled by fitting the following relationship with a least-squares approximation:

$Y_{t}=Y_{0}+b t+N_{t}$

$Y_{t}$ is the deseasonalized monthly median time series, $b$ is the linear trend, $Y_{0}$ is the offset at the start of the time series and $N_{t}$ is the noise term. The noise term $N_{t}$ is further modeled as an $\mathrm{AR}(1)$ process:

$N_{t}=\phi N_{t-1}+\varepsilon_{t}$

Weatherhead et al. (1998) suggested that the standard deviation of the yearly trend $\sigma_{b}$ can be estimated as

$\sigma_{b} \approx \frac{\sigma_{N}}{n^{3 / 2}} \sqrt{\frac{1+\phi}{1-\phi}}$,

where $\sigma_{N}$ is the standard deviation of $N_{t}$ and $n$ equals the total number of years in the series. Weatherhead et al. (1998) also found that if $\left|b / \sigma_{b}\right|>2$, the trend is significant at $95 \%$ significance level, and if $\left|b / \sigma_{b}\right|>1.65$, the trend is significant at the $90 \%$ level (Hsu et al., 2012). In a large number of applications, the least-squares approach is based on the Gaussian distribution of uncertainties. However, a number of studies have pointed out that this assumption is often not appropriate for the analysis of some properties derived in remote sensing applications. For example, O'Neill et al. (2000) suggested using the lognormal distribution as a reference for reporting aerosol optical depth statistics. Moreover, Dubovik and King (2000), and earlier Dubovik et al. (1995), pointed to the importance of using lognormal distribution as a noise assumption in statistically optimized fitting of positively defined physical characteristics. Indeed, the curve of the normal distribution is symmetrical and the assumption of a normal probability density distribution necessarily implies the possibility of negative results arising even in the case of physically nonnegative values (e.g., intensities). For nonnegative characteristics, this assumption is clearly more reasonable. First, lognormally distributed values are positively defined, and a number of theoretical and experimental reasons show that, for positively defined characteristics, the lognormal curve (multiplicative errors; Edie et al., 1971) is closer to reality than normal noise (additive errors; a statistical discussion can be found in Tarantola, 1987). Therefore in the present study, the least-squares fitting for $\mathrm{AOD}$ and $\mathrm{ABS}$ is performed on the logarithm of the data.

\subsection{Analysis example}

Here we show an example of the trends observed by running mean, and estimated using MK/Sen's slope and leastsquares fitting, using level 2.0 direct measurements and inversion products from the Beijing station. Figure 2 displays the deseasonalized time series with 12-month running mean, results of the MK test and Sen's slope, and the linear trend from least-squares fitting for the six parameters. According to Fig. 2, three of the parameters - ABS, SSA and AAE - exhibit statistically significant (statistically significant here and afterwards means statistically significant at the $90 \%$ level) trends, from both MK and least-squares fitting results, while the other parameters do not have significant trends. For ABS, even with a large gap in the time series from 2007 to 2009, a continuous decrease can still be observed from the smoothed time series (black curve in the top panel). The MK test and least-squares fitting results are also consistent in indicating significant negative trends. Similarly, consistent increasing trends are found for SSA. Since AOD does not have significant trends, the decrease in ABS is responsible for the increase in SSA at Beijing. The AAE parameter also shows an increase, although the increase mostly lies in the later part of the time series. Since the mixing of black carbon with other species such as dust and organic carbon tends to increase the AAE value (Russell et al., 2010), this result may imply a reduction in black carbon fraction, which is consistent with the decrease in ABS and increase in SSA. The normal probability plots (normplots) of the least-squares fitting residuals are also presented in Fig. 3, which shows that the residuals follow a normal distribution and thus verifies the validity of least-squares fitting.

\section{Results}

In this section, we focus on presenting and discussing global maps showing the magnitude and significance of the trends of the six variables at each station in the main text; the plots of the trend analysis at each individual station are included in the Supplement. Only statistically significant trends (>90\%) are indicated in the figures. In addition, Tables 1 and 2 list the magnitude and significance of the trends at all stations from the MK and least-squares analysis. The magnitude is shown as Sen's slope while the results of least-squares fitting are indicated as positive or negative. This is due to the fact that least-squares fitting is performed on the logarithm of some parameters so that the magnitude of the trend is not directly comparable to Sen's slope. Comparing the results for MK and least-squares fitting (Tables 1 and 2), we see that the two techniques yield consistent results in the significance for the majority of the cases. In the following discussion, we only present trends that are determined to be significant by both methods as we consider these trends to be the most robust. Note that trends for the level 2.0 AOD globally, and for SSA, 

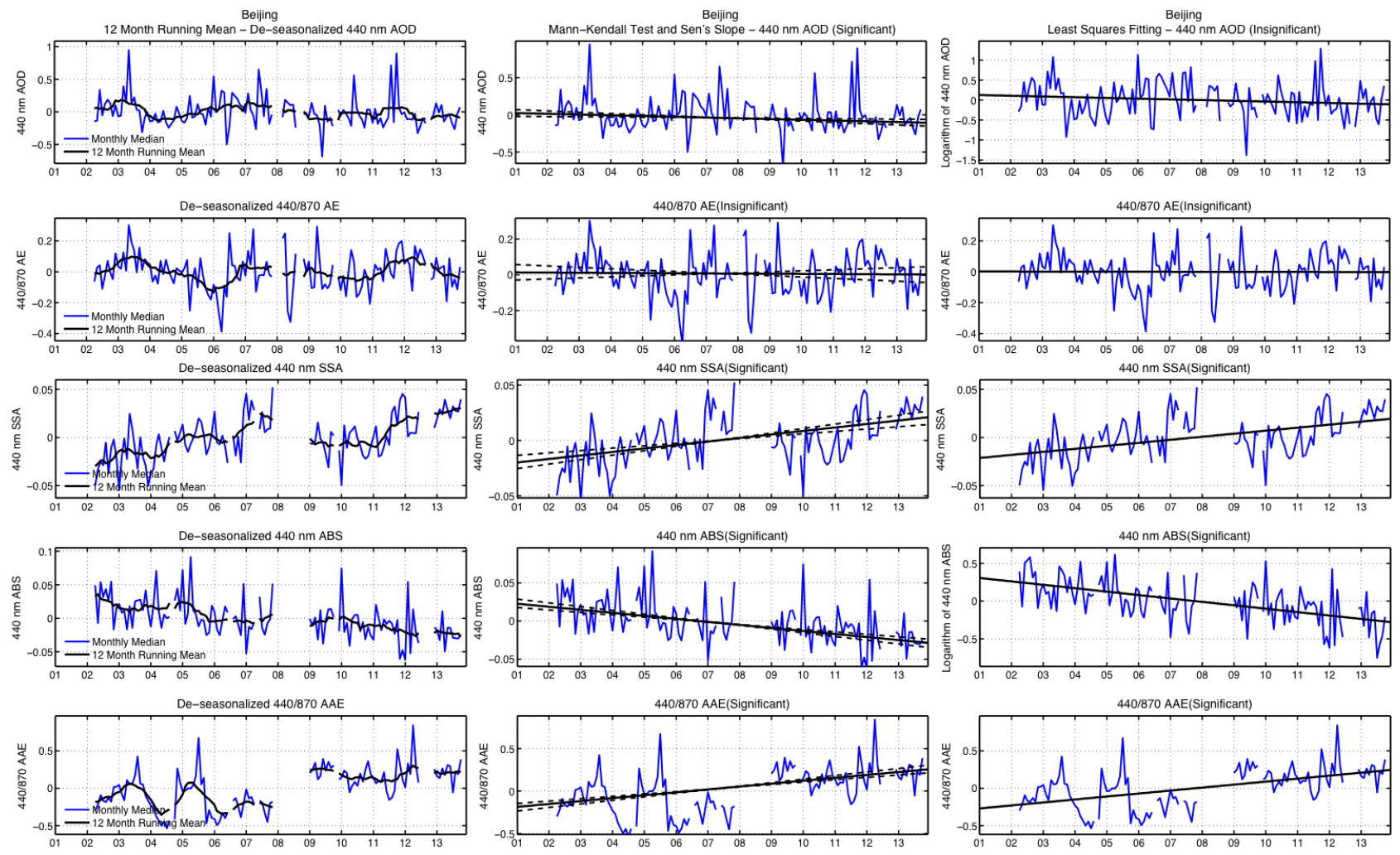

Figure 2. Trend analysis for the six parameters using a 12-month running mean (left column), the Mann-Kendall test associated with Sen's slope (middle column) and least-squares fitting (right column) for the Beijing station using level 2.0 data. The solid black lines in the MK and least-squares fitting results show the linear trend, and the dashed curves in the middle column indicates the $90 \%$ confidence interval of the estimated Sen's slope.
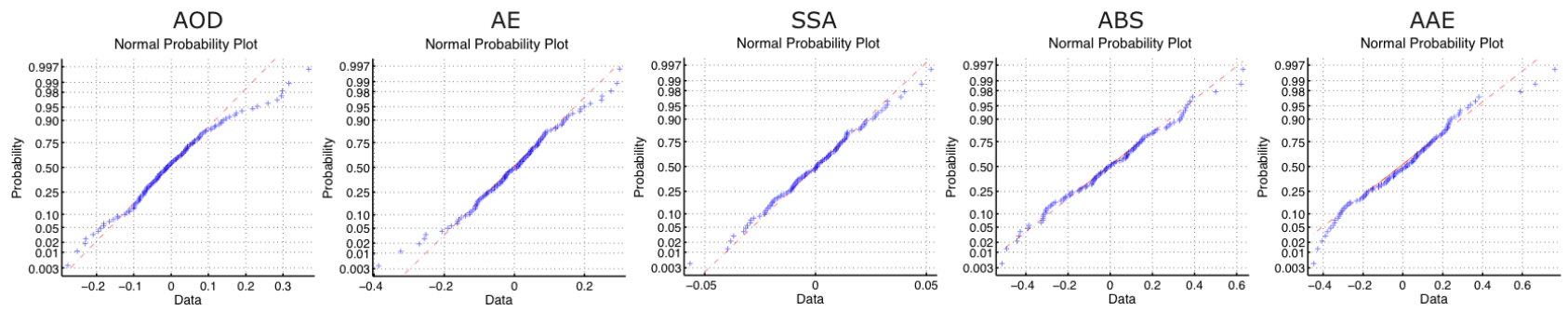

Figure 3. Normplots for the residuals of least-squares fitting shown in the right column of panels of Fig. 2. The majority of the data points concentrate around the red dashed line, indicating that the residuals closely follow a normal distribution.

ABS at the seven level 2.0 stations, are the most reliable; thus emphasis is given to these results.

\subsection{AOD and AE trends}

Statistically significant $440 \mathrm{~nm}$ AOD trends at the 90 selected stations are presented in Fig. 4. The AERONET AOD measurements are highly accurate; therefore the AOD trends are the most robust among the parameters analyzed. Only trends above the $90 \%$ significance level are shown, and larger dots indicate trends above the $95 \%$ significance level. The majority of the stations with significant trends exhibit nega- tive trends in AOD, including most stations in North America and Europe, one biomass burning site in South America (CUIABA-MIRANDA) and two sites in Japan (Osaka and Shirahama). The largest decreases are found over western Europe, reaching $\sim-0.1$ decade $^{-1}$. Strong positive trends are found at Kanpur in North India, and Solar_Village in the Arabian Peninsula.

We also examine the trend for each season, using the MK and least-squares methods on the seasonal mean time series. The results are shown in Fig. 5. In general, the trends are most prominent during the spring (MAM) and summer (JJA) seasons, which usually correspond to the seasons with the 


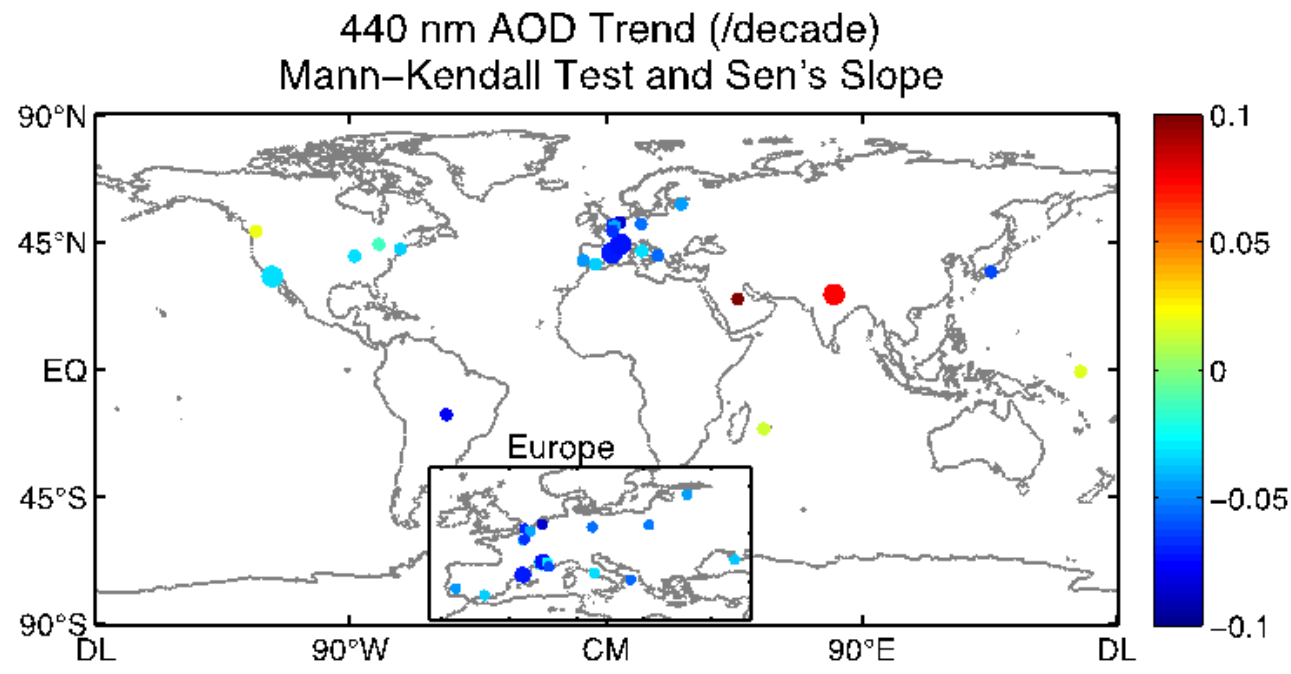

Figure 4. Global map showing the magnitude and significance of the $440 \mathrm{~nm}$ AOD trends. Only statistically significant (>90\%) trends are shown. The smaller dots indicate trends at $90 \%$ significance, while larger dots indicate trends at $95 \%$ significance. The magnitude of the trend $\left(\right.$ decade $\left.^{-1}\right)$ is indicated by the color of the dots, following the color scale on the right. The small panel at the bottom is an enlarged map of Europe.

highest aerosol loading for many locations in the Northern Hemisphere. The patterns on each seasonal trend map agree, in general, with the global results. Some stations only exhibit significant trends for certain seasons. For example, the European and North American stations mostly show significant decreasing trends for the spring (MAM), summer (JJA) and fall (SON). For India, significant trends are found during the fall and winter (DJF). By further examining the time series (figures in the Supplement), it is found that the seasons without significant trends frequently have missing data, which affects or even precludes the detection of trends. Overall, the similarity between the four panels in Fig. 5, and between Figs. 5 and 4, indicates that there is no obvious seasonality in the AOD trends.

In addition to column aerosol loading, the Ångström exponent parameter is an indication of the contribution of fineand coarse-mode aerosols and can also be potentially useful to infer aerosol composition. The global AE trends are shown in Fig. 6. It is interesting to note that while AOD decreased uniformly for both North America and Europe, AE trends are opposite there. North America generally exhibits positive trends, while coherent negative trends are found for Europe. This result suggests a change in the aerosol composition. The AOD reduction in Europe might be due to reduced fine-mode anthropogenic emission, while that for North America might be related to a reduction in natural sources such as coarsemode mineral dust. The AE decrease for the Arabian Peninsula, a major dust source, is consistent with AOD increase, suggesting an increase in dust emission. In addition, the weak positive trend at Kanpur, North India, suggests that increased anthropogenic aerosols are likely the contributor to the positive AOD trend. The seasonal AE trends are shown in Fig. 7.
Like AOD, the trends for the four seasons are also consistent with annual trends. However, note that, different from AOD, which exhibits the most prominent trends in the spring and summer, most AE trends are found during the winter season (DJF). Yet winter usually has the minimum aerosol loading for many Northern Hemisphere locations. The uncertainty in the AE parameter is significantly higher than AOD, especially under low-AOD conditions. According to Kato et al. (2006), the uncertainty in the AE parameter can be estimated as

$\Delta \mathrm{AE}=\left[\frac{\sum_{i=1}^{n} e_{i}^{2}}{(n-1) \sum_{i=1}^{n}\left(\ln \lambda_{i}-\overline{\ln \lambda}\right)^{2}}\right]^{\frac{1}{2}}$,

where $e_{i}$ is the error of the Ångström relation, $n$ is the number of wavelengths $\lambda$ used to calculate $\mathrm{AE}$, and $\overline{\ln \lambda}$ is the average of the logarithm of the wavelengths. The ratio $\frac{\varepsilon_{i}}{\mathrm{AOD}_{i}}$ is used to represent $e_{i} . \varepsilon_{i}$ is the uncertainty of AOD and is specified as 0.01 here. Using Eq. (8) and spectral AOD measurements made at the GSFC site during the study period, we found that the $\mathrm{AE}$ uncertainty during the winter season is 0.56 when the $440 \mathrm{~nm}$ AOD average is 0.08 , while that for the summer is only 0.15 when AOD average is 0.33 . Similar differences in the uncertainty of $\mathrm{AE}$ as a function of season should be expected for most Northern Hemisphere stations with similar seasonal cycles. Therefore, the AE trends under low-AOD conditions such as Northern Hemisphere winter must be evaluated within the context of these increased uncertainties. The same applies to the South America trends during non-peak AOD seasons of summer and winter. 

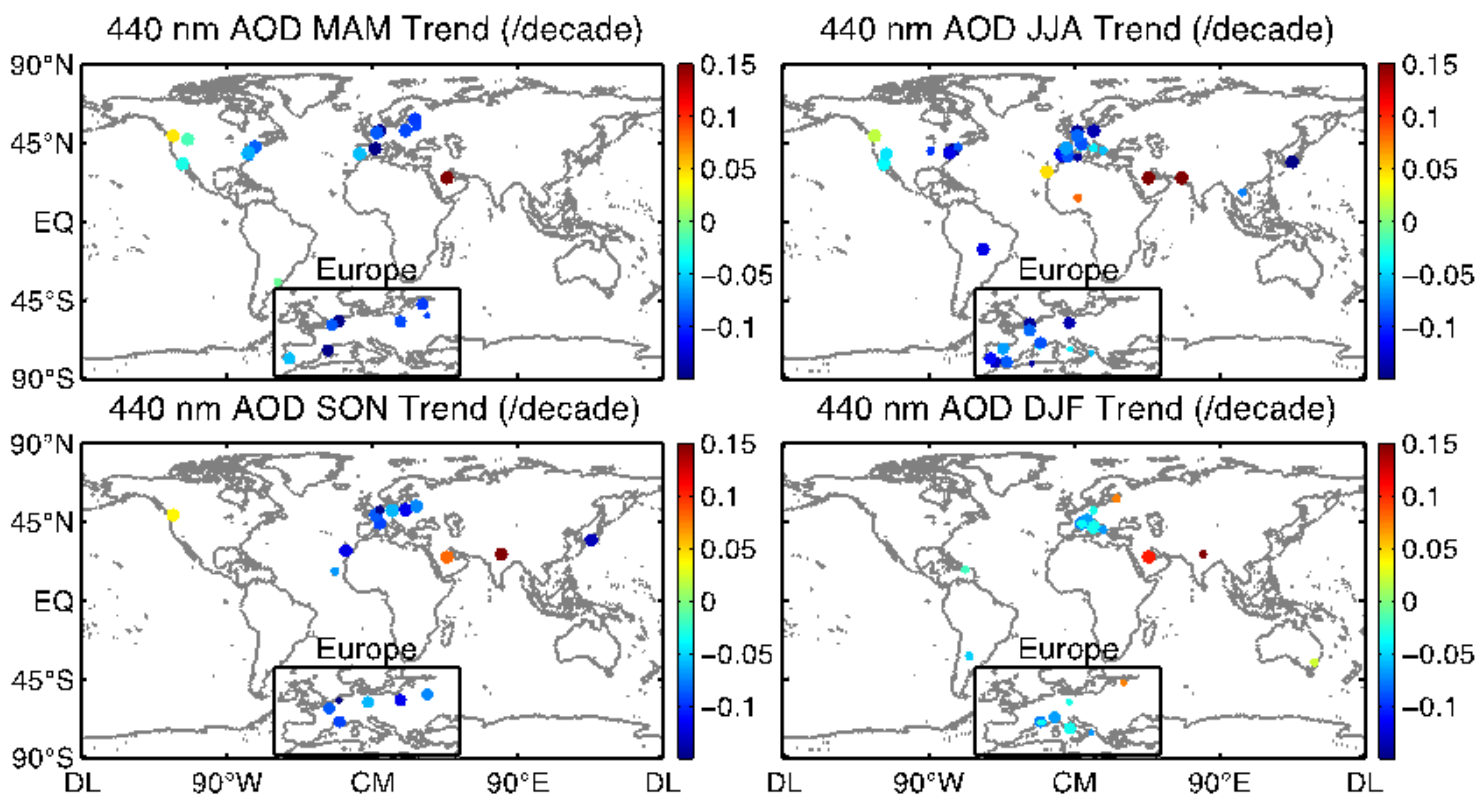

Figure 5. AOD trend maps for the four seasons. MAM: March-April-May; JJA: June-July-August; SON: September-October-November; DJF: December-January-February. Only statistically significant (>90\%) trends are shown. The smaller dots indicate trends at $90 \%$ significance, while larger dots indicate trends at $95 \%$ significance. The magnitude of the trend $\left(\right.$ decade $\left.^{-1}\right)$ is indicated by the color of the dots, following the color scale on the right.

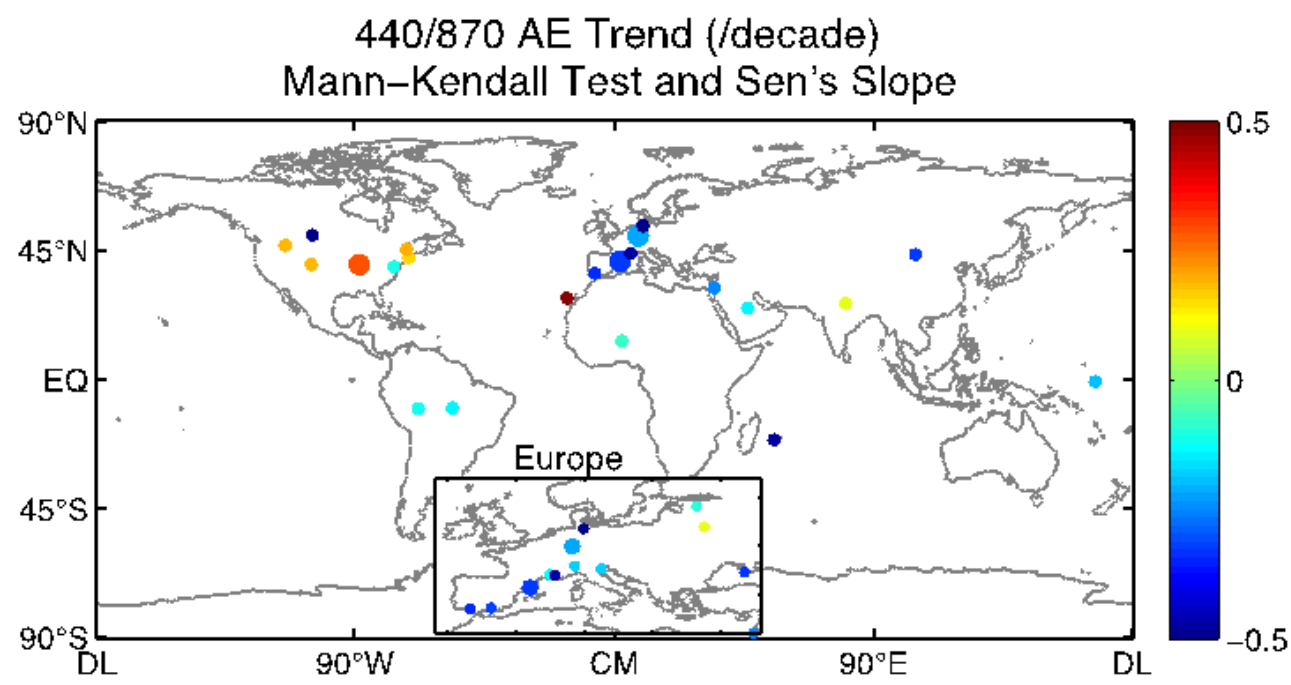

Figure 6. Global map showing the magnitude and significance of the trend in the AE parameter. Only statistically significant ( $>90 \%)$ trends are shown. The smaller dots indicate trends at $90 \%$ significance, while larger dots indicate trends at $95 \%$ significance. The magnitude of the trend $\left(\right.$ decade $\left.^{-1}\right)$ is indicated by the color of the dots, following the color scale on the right.

\subsection{SSA, ABS and AAE trends using level 2.0 data}

Single-scattering albedo and absorption optical depth are closely related, and both indicate the absorption properties of aerosols. These two parameters play even more important roles in aerosol forcing, as the changes in ABS or SSA not only alter direct forcing but also have a potential impact on aerosol-cloud interaction if the changes are associate with aerosol composition change such as trends in black carbon fraction. Additionally, the AAE parameter, defined as the wavelength dependence of ABS,

$$
\mathrm{AAE}=-\log \left(\mathrm{ABS}_{\lambda_{1}} / \mathrm{ABS}_{\lambda_{2}}\right) / \log \left(\lambda_{1} / \lambda_{2},\right)
$$

where $\mathrm{ABS}_{\lambda_{1}}$ and $\mathrm{ABS}_{\lambda_{2}}$ are aerosol absorption optical depth at two wavelengths $\lambda_{1}$ and $\lambda_{2}$, respectively, is also an indicator of aerosol composition, and is determined by the 

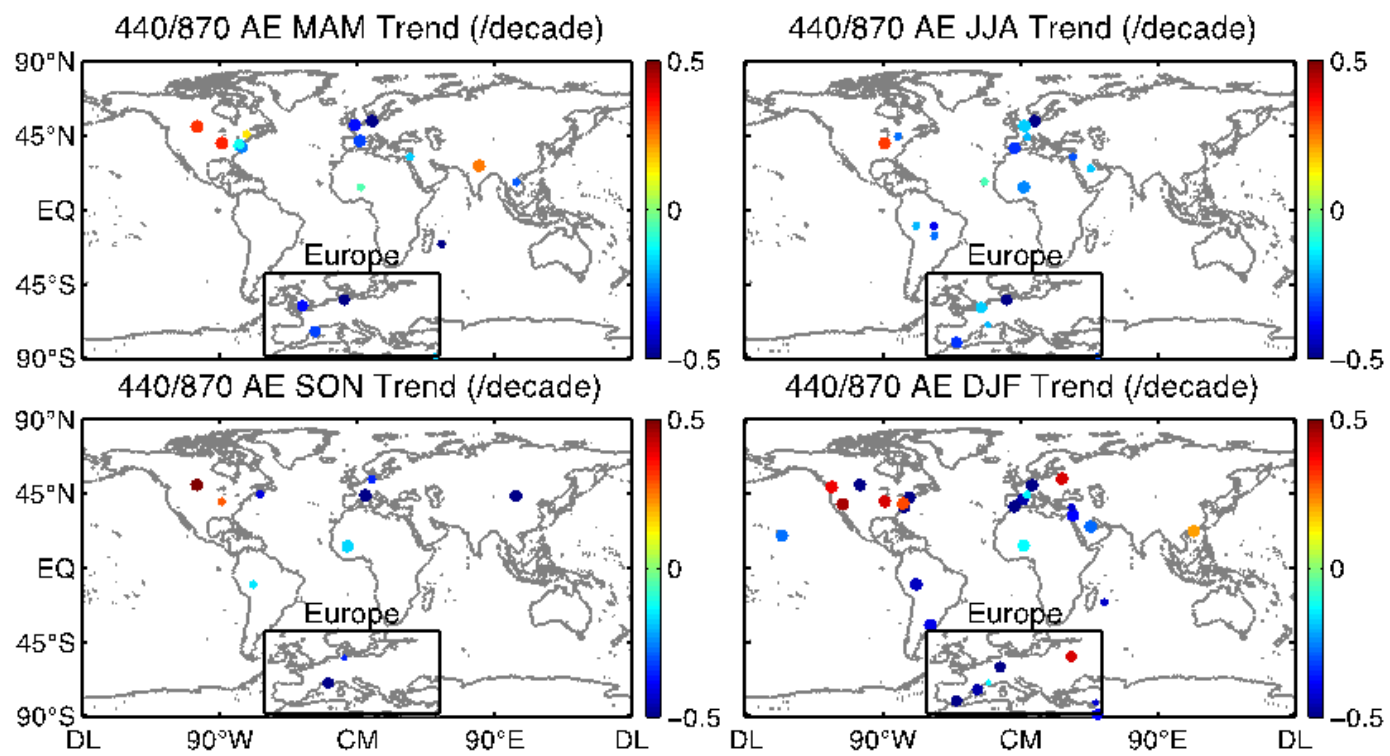

Figure 7. Seasonal trend for the AE.

mixing of different absorbing species, including black carbon, dust and organic carbon aerosols. We therefore examine these three parameters together.

The SSA, ABS and AAE trends for the seven qualified level 2.0 stations are presented in Fig. 8. All of these stations are located in the Northern Hemisphere and are located in major aerosol source regions, including the dust-dominated region of the Arabian Peninsula (Solar_Village) and West Africa (Dakar, IER_Cinzana and Banizoumbou) and heavily polluted areas in North India (Kanpur) and North China (Beijing and XiangHe). Both Beijing and Kanpur show positive SSA trends, while Solar_Village displays a negative trend (Fig. 8a). Beijing, as well as a nearby station - XiangHe, also has decreased ABS. It should be kept in mind that no significant AOD trends are found for Beijing (Fig. 4); therefore the reduction in absorption should be responsible for the increase in SSA. East China has been considered as a region of increased aerosol loading in previous studies (e.g., Wang et al., 2009; Zhang and Reid, 2010; Hsu et al., 2012); here AERONET data indicate that aerosol absorption has actually declined over the past decade for at least two locations. Nonetheless, the ability of only two nearby stations to represent larger-scale patterns is still limited. No significant ABS trend is found for Kanpur. Because this station exhibits a strong increase in AOD (Fig. 4), the positive SSA and AOD trends should be mainly attributed to increased fraction of scattering species, such as sulfates and nitrates. The Solar_Village station also has increased AOD (Fig. 4), and a corresponding increase in ABS as well. Because dust is the primary aerosol species at this location which has strong shortwave absorption, the positive ABS and AOD trends, and negative SSA trends consistently suggest an increase in dust activities. With respect to the AAE, positive trends are ob- served for Beijing and the three stations from West Africa, while Kanpur shows a negative trend. The theoretical value of AAE for black carbon is 1 , and the value increases in the presence of dust and organic carbon (Bergstrom et al., 2002; Russell et al., 2010). The AAE increase in Beijing might be associated with decreased black carbon fraction, which is consistent with previous inferences from the AOD, SSA and ABS trends. The positive AAE trends for West Africa might be associated with increased dust fraction, which tends to raise the AAE value. However, as no spatially coherent AOD or ABS trends are found over this region, the AAE trends are subject to question. The AAE trend for Kanpur seems to suggest an increase in black carbon fraction, which appears to be in contrast to AOD and SSA trends. Note that the AAE parameter has even larger uncertainty levels than the $\mathrm{AE}$, owing to the smaller ABS values and large uncertainties at low aerosol loading. Giles et al. (2012) performed a series of sensitivity of the AAE parameter by perturbing SSA using AERONET measurements, and found that AAE can vary by \pm 0.6 for dust sites with \pm 0.03 perturbation in SSA, which is the uncertainty level for this parameter at level 2.0. Therefore, the AAE trends alone are not sufficient to infer aerosol composition changes and need to be evaluated with other information such as AE and ABS.

Seasonally, the SSA and ABS trends are highly consistent with the annual trend for Beijing and Solar_Village (Fig. 9). Significant decreases in ABS and SSA are observed at Beijing for all seasons. This is a sign of changes in local aerosol source rather than seasonal transport. For Solar_Village, the trend is absent in winter but significant for the other three seasons. The AOD values are lowest in winter at this station, and the absence of the trend is primarily attributed to the lack of level 2.0 data under these low-AOD conditions 


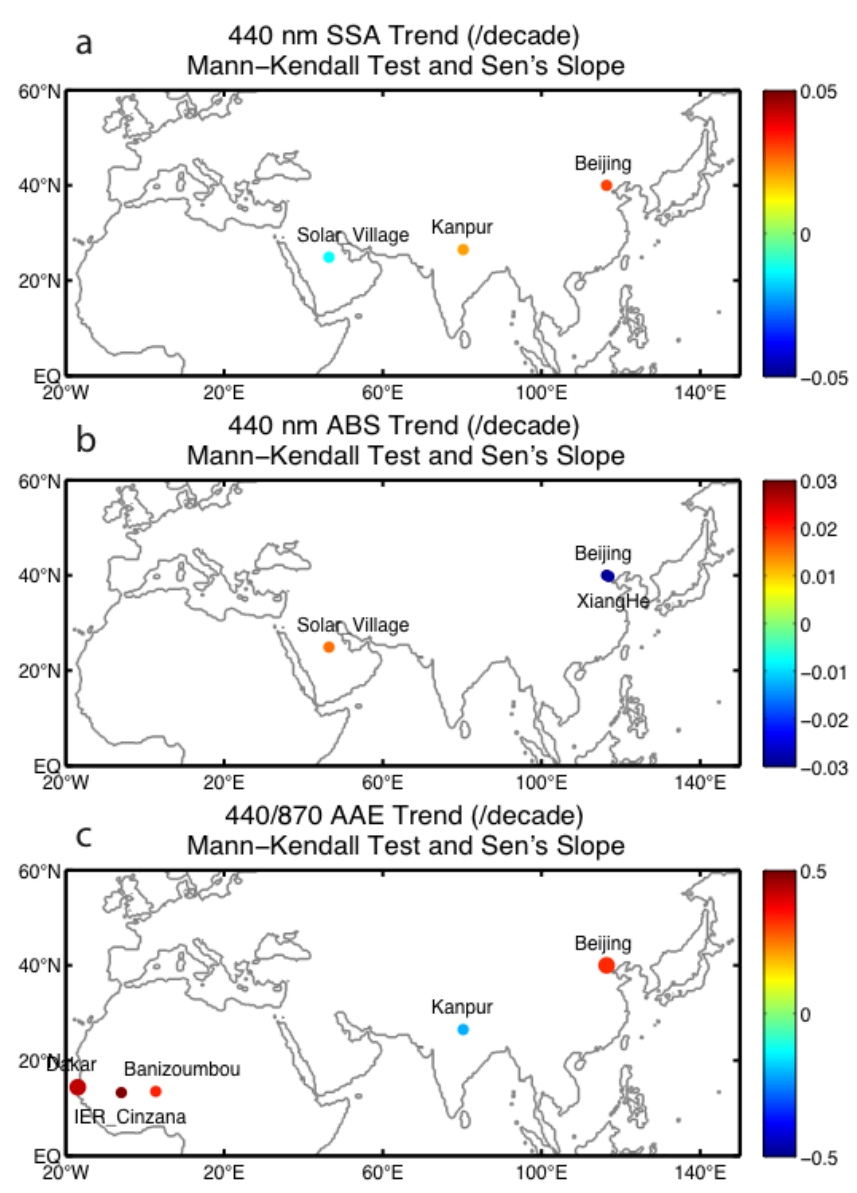

Figure 8. Trends for the SSA (a), ABS (b) and AAE (c) parameters at the seven stations with sufficient level 2.0 inversion data. Only trends above $90 \%$ significance level are shown.

(see the Supplement for the time series). At Kanpur, again no significant change in ABS is found, while the increase in SSA is only observed for the fall and winter. The seasonality of SSA trends is consistent with previously shown AOD seasonal trends (Fig. 5), which is due to the frequently missing data during the spring and summer. One the other hand, the seasonality of the trends also indicates possible changes in anthropogenic aerosol emissions, the dominant aerosol type over North India during the post-monsoon and winter season (e.g., Corrigan et al., 2006). The positive trend in AAE is also present in all seasons, supporting the argument of decreased black carbon fraction. The seasonality for the three West Africa stations, however, is not consistent. Dakar shows positive trends during the spring, summer and fall, and IER_Cinzana during the winter, while Banizoumbou displays a negative trend during the fall. This spatial discrepancy further confounds the understanding of the results. Considering the large uncertainty in the AAE, more information, such as that from in situ measurements of aerosol physical and optical properties, is needed to fully resolve the change in aerosol composition.

\subsection{SSA, ABS and AAE trends using level 1.5 data}

As shown in the last section, only seven stations have sufficient level 2.0 inversion data for long-term trend analysis. The location and aerosol types of these stations are far from enough to represent aerosol variability on a global basis. Observations at many other places are needed to address interesting questions regarding the effects of pollution control measures taken in developed regions, including Europe, North America and Japan, and changes in biomass burning emissions in the Southern Hemisphere. Although ideally we would prefer to use level 2.0 data only, the AOD threshold of 0.4 applied to the data, as required by the quality assurance criteria (Holben et al., 2006), eliminates the bulk of the data, especially for the abovementioned regions, where aerosol loading is typically low. In Fig. 9 we plot the distribution of AERONET AOD (from level 2.0 direct sun measurements) globally and for five regions, using the stations selected for this study. The small panel in the upper-right corner of each larger panel shows the enlarged distribution for the $[0,0.5]$ AOD interval, and the threshold value of 0.4 is marked by black dashed lines. We can clearly see that the AOD $>0.4$ portion only captures the tail of the AOD distribution, while the bulk of the data fall between 0 and 0.4. Even for Africa and Asia, where AOD are, in general, larger, the 0.4 cutoff will still eliminate roughly $75 \%$ of the data. Since there are currently no other SSA or ABS measurements with comparable spatial and temporal coverage to AERONET, here we also show the results of an analysis of the more-uncertain level 1.5 inversion products in order to provide greater spatial coverage, which may serve as a reference for future studies when better quality data become available. However, the reader should keep in mind that level 1.5 data are subject to larger uncertainty when interpreting these results. Only annual trends are shown. Seasonal trend maps can be found in the Supplement.

Figure 10 shows the global SSA, ABS and AAE trends for level 1.5 data. The seven level 2.0 stations are also included, but level 1.5 data were used for producing Fig. 10. This is for the purpose of evaluating the effect of AOD cutoff on the trend estimate. Globally, positive SSA trends are found at the majority of the stations, in particular Europe, North America and Asia. Correspondingly, ABS is found to have decreased over these regions, with the strongest decrease over Europe reaching $\sim-0.03 \mathrm{decade}^{-1}$. Solar_Village and three Southern Hemisphere stations exhibit negative SSA and positive ABS trends. The AAE trends are less spatially coherent, which is more likely due to larger uncertainty associated with that parameter. Moreover, by comparing Fig. 11 with Fig. 9 for the seven level 2.0 stations, we find that the sign and significance of the trends are highly consistent, although the absolute magnitudes may differ due to changes in sampling. (Note that the color scales for Figs. 8 and 10 are different in order to accommodate additional level 1.5 stations with larger trends.) One can further refer to the Supplement 


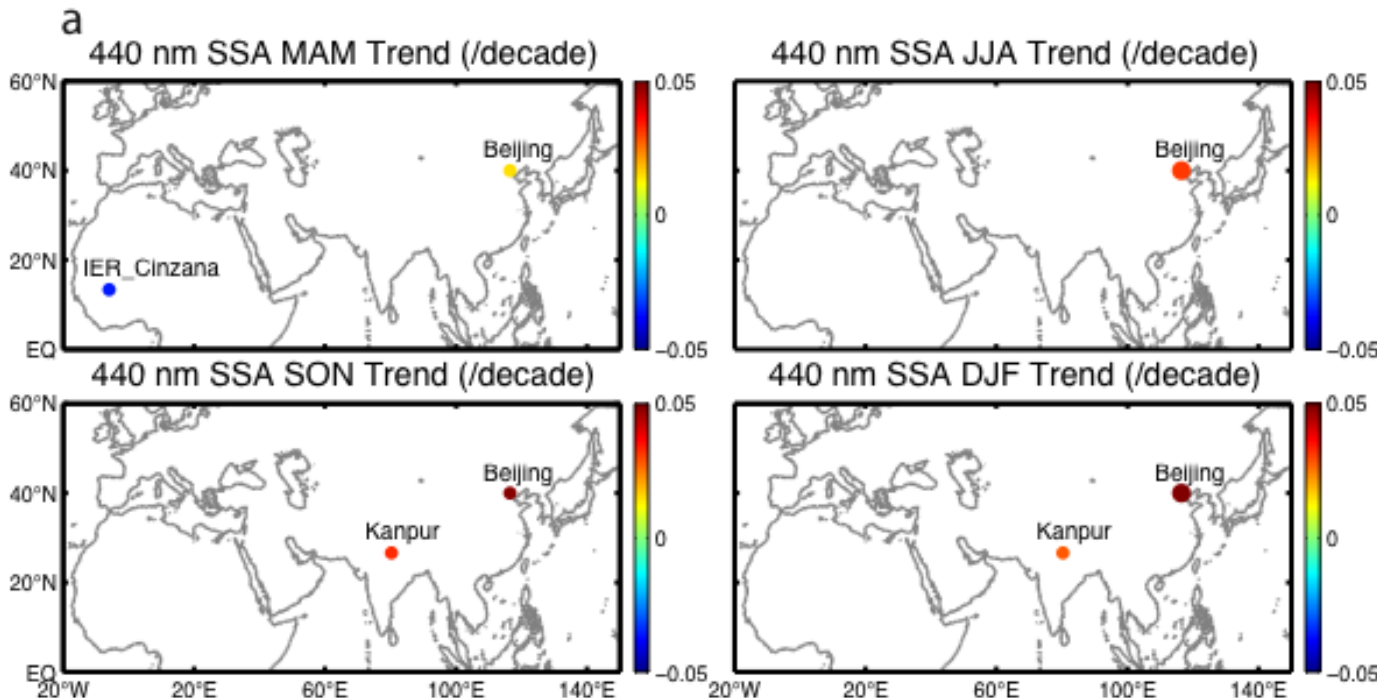

b
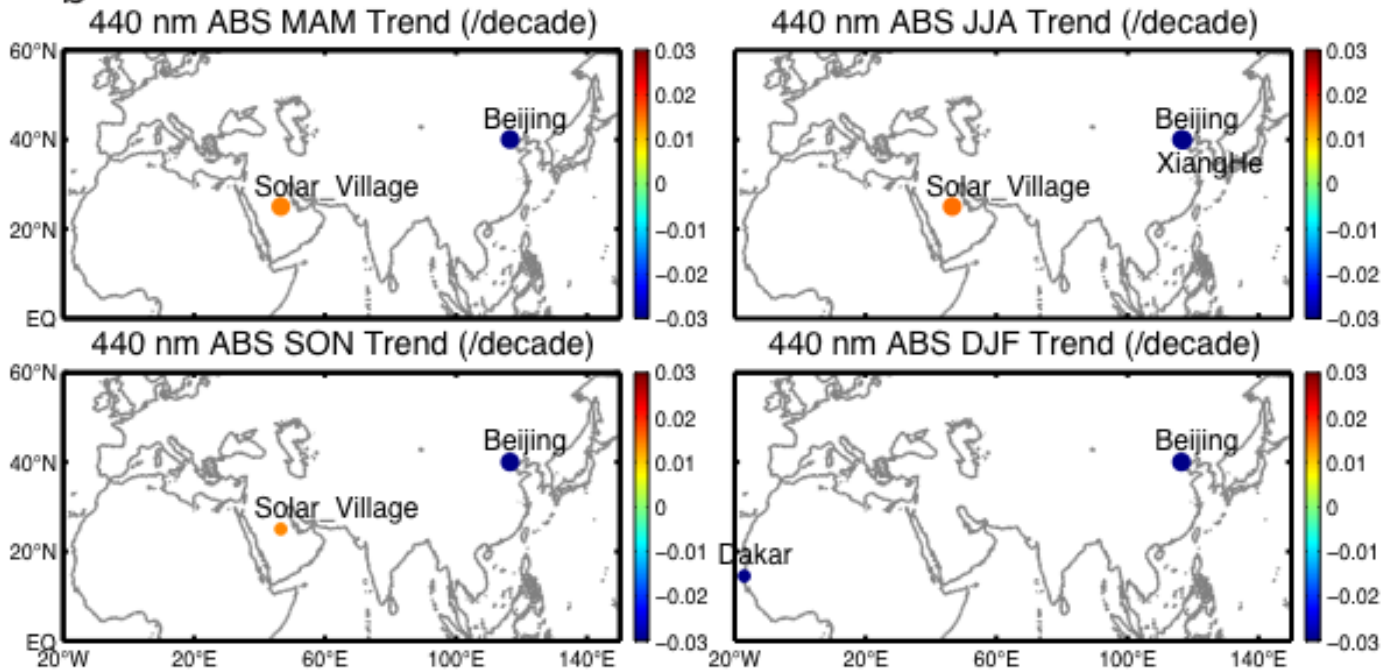

C

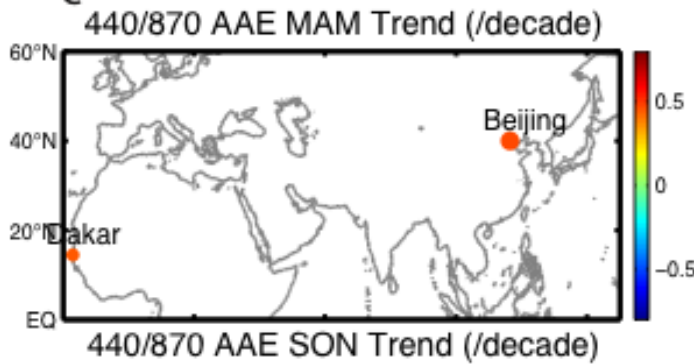

440/870 AAE JJA Trend (/decade)
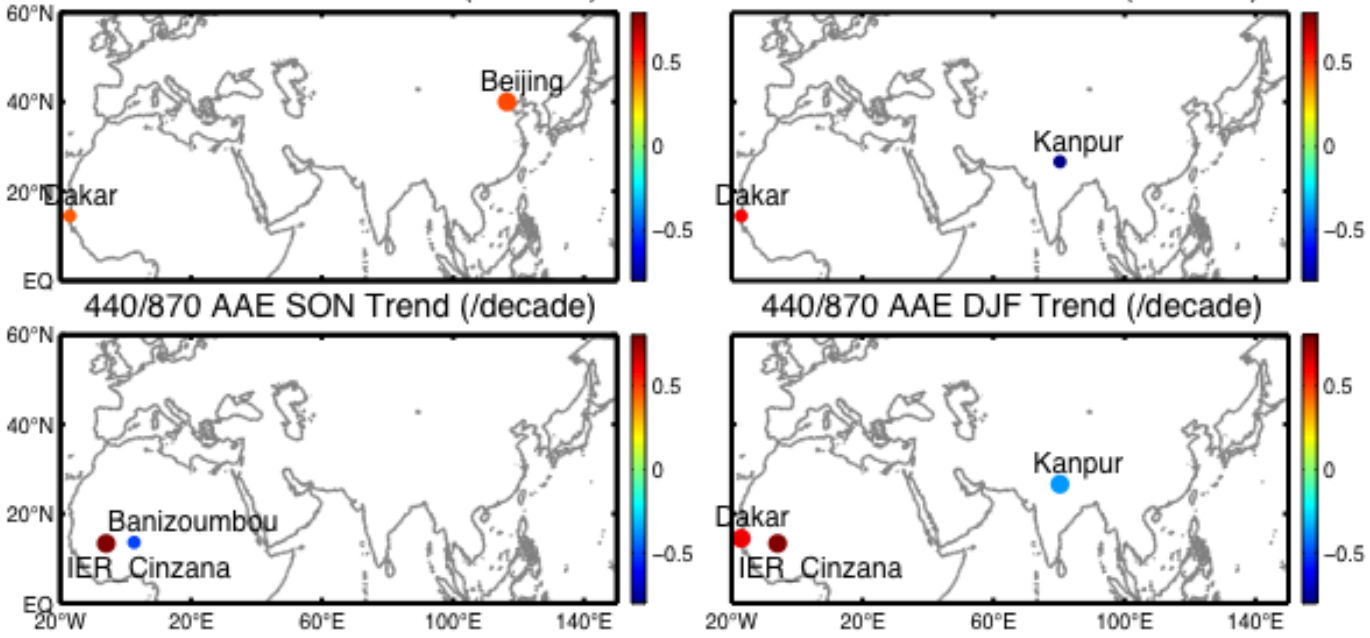

Figure 9. Seasonal trends for SSA (a), ABS (b) and AAE (c) at the level 2.0 stations. Only statistically significant ( $>90 \%)$ trends are shown. The smaller dots indicate trends at $90 \%$ significance, while larger dots indicate trends at $95 \%$ significance. The magnitude of the trend $\left(\right.$ decade $\left.^{-1}\right)$ is indicated by the color of the dots, following the color scale on the right. 

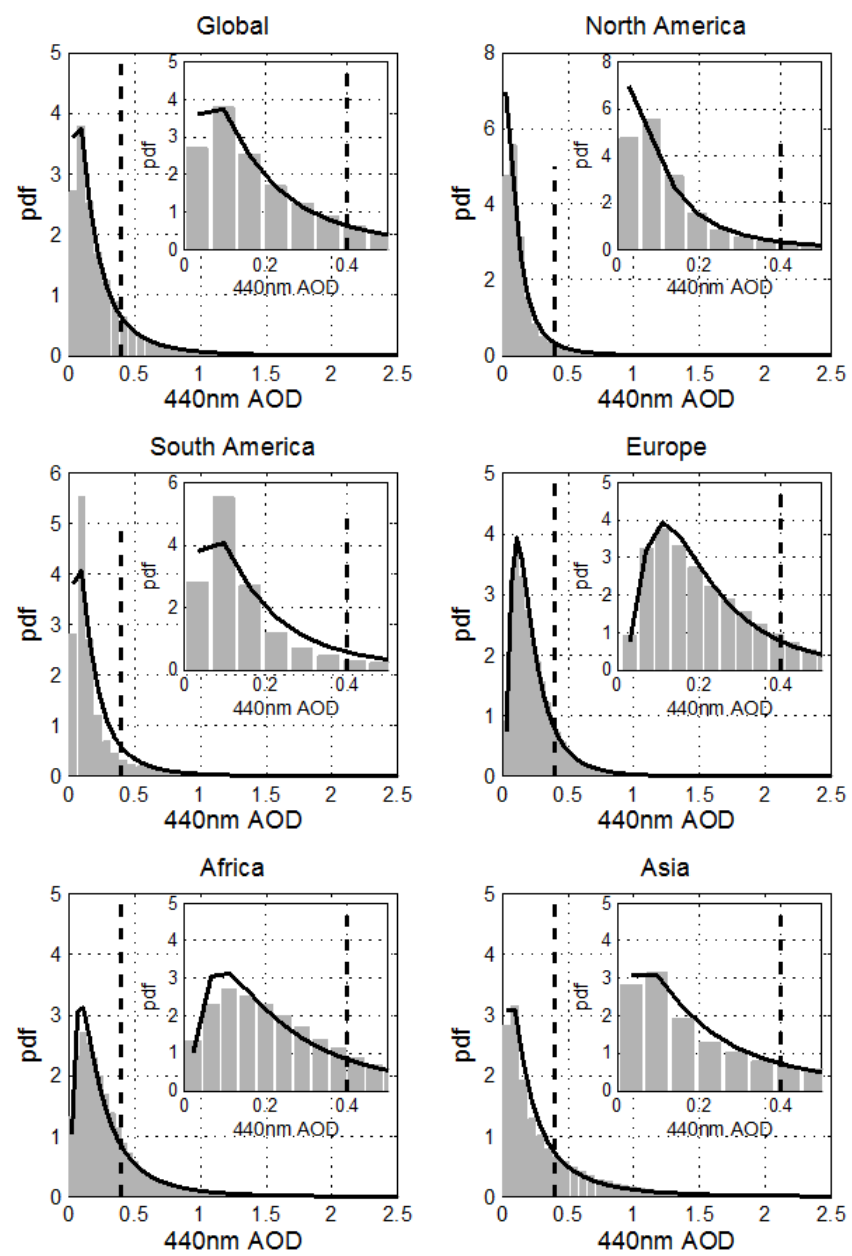

Figure 10. Global and regional $440 \mathrm{~nm}$ AOD distributions using data from the 90 stations used here in the AOD and $\mathrm{AE}$ trend study. The smaller panels in the upper right show an enlargement of the [0, 0.5] AOD interval. The black dashed line marks the position of $\mathrm{AOD}=0.4$, which is the quality control threshold used for AERONET level 2.0 inversion product.

and compare the level 1.5 and level 2.0 time series for these stations.

Figure 10 is produced without any AOD thresholds. Only solar zenith angle and sky error criteria are used to screen the data. As the errors in these parameters, especially the SSA and AAE, increase as AOD becomes lower, we further repeat the analysis using an intermediate AOD threshold of 0.2 to increase some reliability. However, this screening results in a loss of roughly $60 \%$ of the data, and only 12 stations are left with sufficient data for analysis. The SSA, AAE and ABS trends for these stations also agree with their level 1.5 trends without screening (Fig. 10). The level 2.0 trends at the stations shown in Fig. 8 are also consistent with Fig. 10. The only exception is the Banizoumbou station, where SSA trends become insignificant at level 2.0. In fact, Dubovik et al. (2000) performed a series of sensitivity studies, and

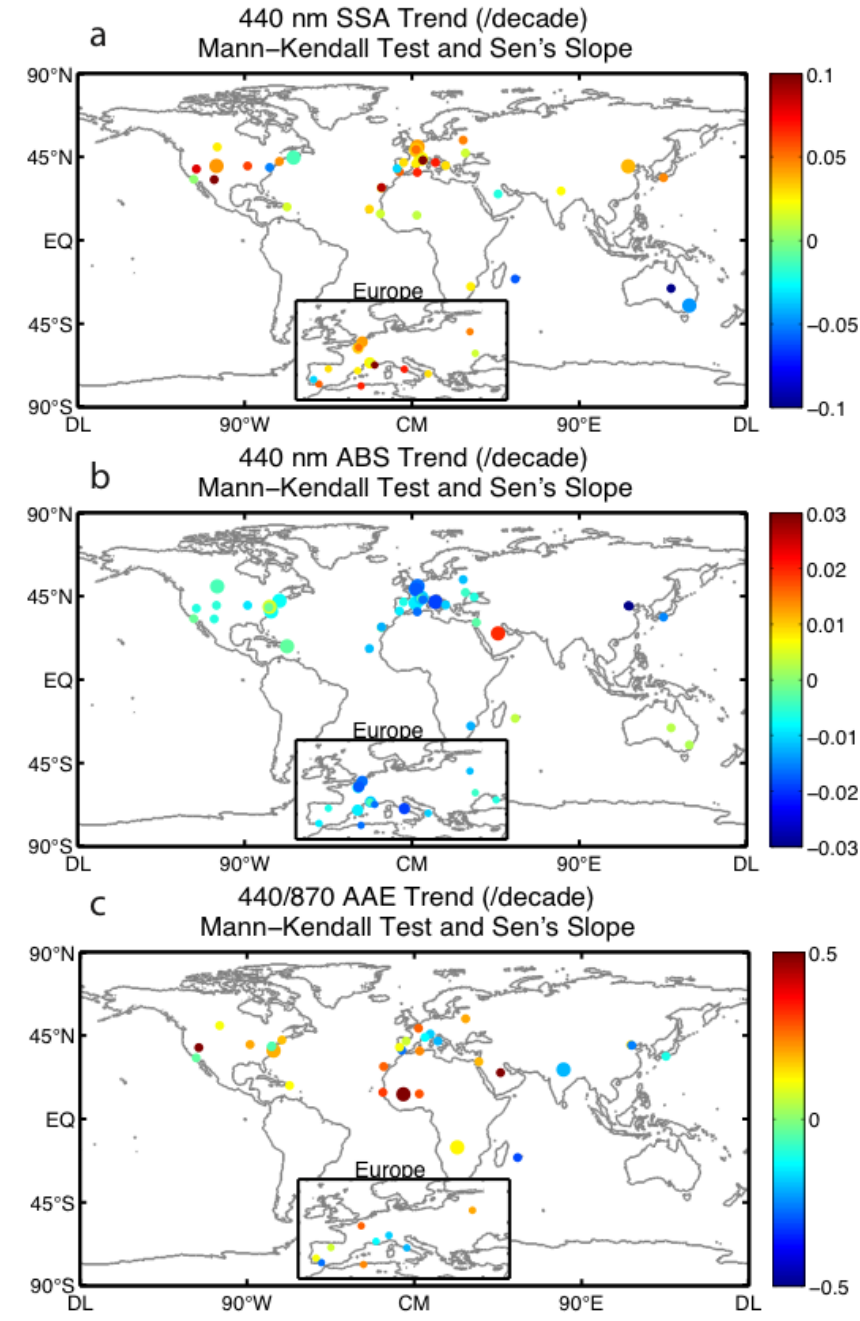

Figure 11. Global SSA (a), ABS (b) and AAE (c) trends using level 1.5 data. Only statistically significant $(>90 \%)$ trends are shown. The smaller dots indicate trends at $90 \%$ significance, while larger dots indicate trends at $95 \%$ significance. The magnitude of the trend (decade ${ }^{-1}$ ) is indicated by the color of the dots, following the color scale on the right.

while they suggested a drop in the accuracy of AERONET retrievals at lower AODs, they did not find any biases due to assumptions in the retrieval model.

The consistency in level 1.5, level 1.5 screened with AOD $>0.2$, and level 2.0 trends, together with spatial coherency of the level 1.5 trends for North America and Europe, increases our confidence in the trends estimated using level 1.5 data. However, neither the level 2.0 nor the level 1.5 results should be considered to represent the ground truth. Although level 2.0 data are accurate, the analysis is biased towards areas and conditions of large aerosol loading, while missing some other important information. A typical example is measurements at island stations, which are more representative of global background aerosol and are important in understanding aerosol 


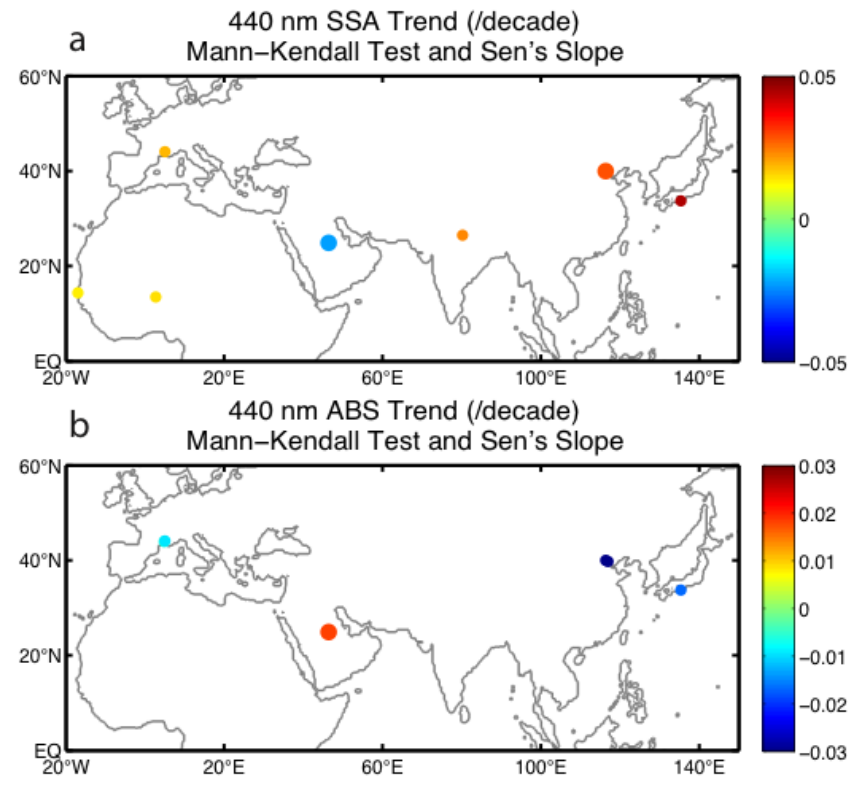

440/870 AAE Trend (/decade)

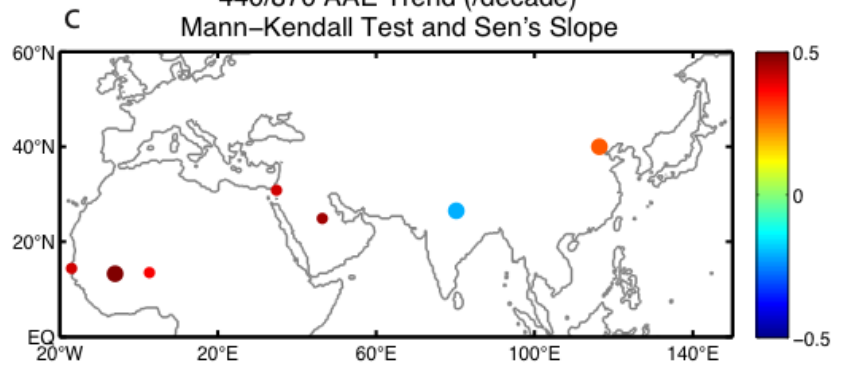

Figure 12. SSA (a), ABS (b) and AAE (c) trends for the 12 stations selected with AOD $>0.2$ threshold. Only statistically significant $(>90 \%)$ trends are shown. The smaller dots indicate trends at $90 \%$ significance, while larger dots indicate trends at $95 \%$ significance. The magnitude of the trend $\left(\right.$ decade $\left.^{-1}\right)$ is indicated by the color of the dots, following the color scale on the right.

climate forcing, yet the AODs are usually too low for the inversion products to be reliable. Therefore, improvements in AERONET data quality control are needed to ensure data accuracy without losing too much spatial and temporal coverage. The spatial correlation of the measurements, such as the consistent trends for all stations in Europe shown above, might be a helpful factor, although this information is only available for limited places where the AERONET network is sufficiently dense.

\section{Discussion}

The significant decline found in AERONET AOD over Europe, North America and Japan is consistent with studies using satellite remote sensing products (e.g., Zhang and Reid, 2010; Hsu et al., 2012) and visibility data (Wang et al., 2009), as well as independent studies using level 2.0 AERONET direct beam retrievals (Xia et al., 2011; Yoon et al., 2012).
The sign of the level 1.5 ABS and SSA trends is also in good agreement with trends in aerosol scattering and absorption coefficients derived from in situ measurements reported by Collaud Coen et al. (2013), although Collaud Coen et al. (2013) suggested a stronger decline in scattering coefficients for North America than Europe, and also less significant trends in absorption than scattering, while the AERONET data indicate significant decreases in both scattering and absorption, and comparable trends for North America and Europe. These differences may stem from several factors. For example, Collaud Coen et al. (2013) utilize surface in situ sampling data, while the AERONET data represent the atmospheric column. Also, most of the sites in Collaud Coen et al. (2013) are remote sites, while many of the selected AERONET stations are urban. The timing of these trends also appears to be in line with emission control measures that have taken place in Europe and North America during the past decades. In the US, $\mathrm{PM}_{2.5}$ has been estimated to have been reduced by $50 \%$, and $\mathrm{SO}_{2}$ by $55 \%$ (EPA, 2011). Murphy et al. (2011) found significant decreases in both $\mathrm{PM}_{2.5}$ and elemental carbon using data from the IMPROVE network. Reductions in $\mathrm{PM}_{2.5}$ and $\mathrm{SO}_{2}$ are also reported for Europe (Tørseth et al., 2012), although the decrease is weaker than that found for the US

The positive SSA trends found over East Asia (East China and Japan) agree with the results of a previous study by Lyapustin et al. (2011) also using AERONET data and with the results of an analysis of independent measurements by Kudo et al. (2010). The reduction of ABS for the Chinese stations, especially Beijing, seems somewhat controversial in light of the trends in emission inventories. For example, $\mathrm{Lu}$ et al. (2011) indicated an increase in $\mathrm{SO}_{2}$ emission in China of $62 \%$ from 2000 to 2006, with a decrease of $9.2 \%$ from 2006 to 2010, while black carbon and organic carbon emissions increased by 72 and $43 \%$, respectively, from 2000 to 2010. Zhang et al. (2009) also suggested emission growth by $13-55 \%$ from 2001 to 2006 for most species, including $\mathrm{SO}_{2}$ and black carbon. As the results presented here are only from two nearby stations - Beijing and XiangHe - the representativeness of the results is quite limited. Moreover, the aerosol properties in Beijing are perturbed by the air quality control measures during the Olympic Games (e.g., Cermak and Knutti, 2009; Zhang et al., 2009; Guo et al., 2013), which may be one of the reasons for the observed decline in ABS. However, difficulty arises as most of the AERONET stations in China were established in recent years and their records are not long enough for trend analysis, while satellite remote sensing techniques are not capable of retrieving absorption properties. More observation-based trend analyses for China may become possible in the next few years once more of the stations have longer-term measurements.

The positive AOD trends found at Kanpur, India, are consistent with studies using satellite remote sensing products (Dey and Girolamo, 2011; Ramachandran et al., 2012) and independent ground-based measurements (Babu et al., 2013). 
The AERONET results presented here imply that scattering aerosols are primarily responsible for this increase in AOD. The increase in aerosol scattering also largely agrees with positive trends in $\mathrm{SO}_{2}$ over India, as reported by $\mathrm{Lu}$ et al. (2013) and Mallik et al. (2013).

The increase in AOD at the Solar_Village station is corroborated by satellite observation (Hsu et al., 2012; Chin et al., 2014) and transport model results (Chin et al., 2014). AERONET data further verify that the change is due to increased dust emission with negative AE trend, negative SSA and positive ABS trend.

Particular attention should be paid to the trend in SSA as revealed by AERONET data. Whether changes in atmospheric aerosol loading will induce a heating or cooling effect on the climate heavily depends on the SSA parameter. It is believed that there is a critical value of the SSA above which aerosols produce a negative forcing (cooling), and below which the aerosol produce a positive forcing (warming). Hansen et al. (1997) concluded from general circulation model experiments that aerosols with SSA up to 0.9 would lead to global warming, and that the anthropogenic aerosol feedback on the global mean surface temperature is likely to be positive. Ramanathan et al. (2001) indicated for SSA $<0.95$ that aerosol net forcing can change from negative to largely positive depending on aerosol height, surface albedo and cloud conditions. Moreover, the change in this parameter implies changes in the relative fraction of absorbing species (mainly black carbon) with respect to scattering aerosols, which may have a broad impact on their total radiative effect. Ramana et al. (2010) found that the warming of black carbon strongly depends on the ratio of black carbon to sulfate aerosols. Therefore, the change in SSA for many locations implies a potentially larger change in the aerosol forcing. In particular, while the recent increase in surface radiation, or global brightening, found for Europe, North America and Japan has been largely attributed to the reduction of total aerosol loading, the increase in SSA could also contribute to this trend (Kudo et al., 2010).

Another important consequence of trends in SSA is the impact of aerosol properties on satellite-retrieved trends. As most satellite retrieval algorithms assume constant SSA values for the aerosol models, systematic changes in SSA over time may produce spurious tendencies in the retrieved AOD (Mishchenko et al., 2007). Lyapustin et al. (2012) indicated that the temporal change in the bias between MODIS and AERONET AOD over Beijing can be explained by the increase in SSA at this station. Mishchenko et al. (2012) showed that decreasing SSA in the AVHRR AOD retrieval by 0.07 from the start to the end of the data record could eliminate the downward trend in the data. Therefore, the trends in SSA revealed by AERONET measurements should be taken into account in the retrieval algorithms to yield a more accurate representation of temporal changes in aerosol loading.

Admittedly, the AERONET data are not perfect. Several limitations may affect the accuracy of the trend analysis pre- sented here. In addition to the larger uncertainties associated with low-AOD conditions for AE, SSA, ABS and AAE, the spatial representativeness of the stations is also a factor that should be considered when evaluating the trends at each individual station. Many of the stations selected here are urban sites, where aerosol properties tend to be highly variable due to the influence of many local emission sources. For example, some nearby stations in Europe have opposite trends in the ABS and SSA, which suggests that they may be dominated by different local sources and aerosol types. To address this problem, more efforts should be made to maintain longterm, continuous monitoring of aerosol properties at remote locations. Nonetheless, to date, AERONET is the most extensive ground-based aerosol observation network with high retrieval accuracy, and the trends presented here are significant according to both the MK test and least-squares fitting methods. Both these factors improve the robustness of the results.

\section{Conclusions}

In this study, we presented the results of a trend analysis of key aerosol properties retrieved from AERONET measurements. Although trends in total aerosol loading such as AOD have been extensively investigated, fewer studies can be found for the absorption and scattering properties. This work therefore serves as a reference for evaluating recent changes in aerosol forcing and the assessment of emission inventories and emission control measures. The major conclusions are summarized below:

- Significant decreases in AOD are found for most locations, in particular, North America, Europe and Japan. The Kanpur station in North India and Solar_Village in the Arabian Peninsula experienced increases in AOD.

- The AE parameters exhibit positive trends over North America but negative trends over Europe, suggesting decreases in natural and anthropogenic aerosols are responsible for the AOD reduction over these two regions, respectively.

- AERONET level 2.0 inversion products reveal increases in SSA and decreases in ABS for Beijing and Solar_Village. Positive SSA trend is also observed for Kanpur but is attributed to the increase in scattering aerosols.

- Level 1.5 inversion data are also analyzed for a broader spatial coverage. Spatially uniform increases in SSA are found for Europe and North America, associated with decreases in ABS. For the seven stations with qualified level 2.0 data, the trends are consistent at level 1.5, level 1.5 with AOD $>0.2$ threshold, and level 2.0.

- No obvious seasonal dependence is found for any of the trends. 
Finally, it is important to restate that level 1.5 results presented here are subject to large uncertainty. Moreover, except for the AOD, the parameters also have large uncertainties under low-AOD conditions, even for level 2.0. The exceptions are sites with very high AOD such as Beijing, Kanpur, XiangHe, IER Cinzana, Banizoumbou, Solar_Village and Dakar, where very high AOD levels allow for accurate retrievals of all parameters analyzed. With the further development of the AERONET algorithm, such as the release of version 3 data in the near future, a more accurate estimation will become possible.

\section{The Supplement related to this article is available online at doi:10.5194/acp-14-12271-2014-supplement.}

Acknowledgements. We thank the AERONET team, especially the PIs of the 90 selected stations, for providing the data used in this study. The AERONET data are obtained from the AERONET website, http://aeronet.gsfc.nasa.gov/. This study was funded by NASA climate grant 509496.02.08.04.24. Jing Li also acknowledges Hal Maring and the NASA Radiation Science program for providing funding for this investigation.

Edited by: S. Kazadzis

\section{References}

Babu, S. S., Manoj, M. R., Krishna Moorthy, K., Gogoi, Mukunda M., Nair, Vijayakumar S., Sobhan Kumar Kompalli, Satheesh, S. K., Niranjan, K., Ramagopal, K., Bhuyan, P. K., and Darshan Singh: Trends in aerosol optical depth over Indian region: Potential causes and impact indicators, J. Geophys. Res. Atmos., 118, 11794-11806, 2013.

Bergstrom, R. W., Russell, P. B., and Hignett, P. B.: The wavelength dependence of black carbon particles: predictions and results from the TARFOX experiment and implications for the aerosol single scattering albedo, J. Atmos. Sci., 59, 567-577, 2002.

Cermak, J. and Knutti, R.: Beijing Olympics as an aerosol field experiment, Geophys. Res. Lett., 36, L10806, doi:10.1029/2009GL038572, 2009.

Charlson, R. J., Schwartz, S. E., Hales, J. M., Cess, R. D., Coakley, Jr., J. A., Hansen, J. E., and Hoffman, D. J.: Climate forcing by anthropogenic aerosols, Science, 255, 423-430, 1992.

Chin, M., Diehl, T., Tan, Q., Prospero, J. M., Kahn, R. A., Remer, L. A., Yu, H., Sayer, A. M., Bian, H., Geogdzhayev, I. V., Holben, B. N., Howell, S. G., Huebert, B. J., Hsu, N. C., Kim, D., Kucsera, T. L., Levy, R. C., Mishchenko, M. I., Pan, X., Quinn, P. K., Schuster, G. L., Streets, D. G., Strode, S. A., Torres, O., and Zhao, X.-P.: Multi-decadal aerosol variations from 1980 to 2009: a perspective from observations and a global model, Atmos. Chem. Phys., 14, 3657-3690, doi:10.5194/acp14-3657-2014, 2014.
Collaud Coen, M., Andrews, E., Asmi, A., Baltensperger, U., Bukowiecki, N., Day, D., Fiebig, M., Fjaeraa, A. M., Flentje, H., Hyvärinen, A., Jefferson, A., Jennings, S. G., Kouvarakis, G., Lihavainen, H., Lund Myhre, C., Malm, W. C., Mihapopoulos, N., Molenar, J. V., O’Dowd, C., Ogren, J. A., Schichtel, B. A., Sheridan, P., Virkkula, A., Weingartner, E., Weller, R., and Laj, P.: Aerosol decadal trends - Part 1: In-situ optical measurements at GAW and IMPROVE stations, Atmos. Chem. Phys., 13, 869-894, doi:10.5194/acp-13-869-2013, 2013.

Corrigan, C. E., V. Ramanathan, and J. J. Schauer: Impact of monsoon transitions on the physical and optical properties of aerosols, J. Geophys. Res., 111, D18208, doi:10.1029/2005JD006370, 2006.

Dey, S., and Di Girolamo, L.: A decade of change in aerosol properties over the Indian subcontinent, Geophys. Res. Lett., 38, L14811, doi:10.1029/2011GL048153, 2011.

Dubovik, O. and King, M. D.: A flexible inversion algorithm for retrieval of aerosol optical properties from Sun and sky radiance measurements, J. Geophys. Res., 105, 20673-20696, 2000.

Dubovik, O., Smirnov, A., Holben, B. N., King, M. D., Kaufman, Y. J., Eck, T. F., and Slutsker, I.: Accuracy assessments of aerosol optical properties retrieved from AERONET Sun and sky-radiance measurements, J. Geophys. Res., 105, 9791-9806, 2000.

Dubovik, O., Holben, B. N., Eck, T. F., Smirnov, A., Kaufman, Y. J., King, M. D., Tanré, D., and Slutsker, I.: Variability of absorption and optical properties of key aerosol types observed in worldwide locations, J. Atmos. Sci., 59, 590-608, 2002.

Dubovik, O., Sinyuk, A., Lapyonok, T., Holben, B. N., Mishchenko, M., Yang, P., Eck, T. F., Volten, H., Munoz, O., Veihelmann, B., van der Zander, W. J., Sorokin, M., and Slutsker, I.: Application of light scattering by spheroids for accounting for particle nonsphericity in remote sensing of desert dust, J. Geophys. Res., 111, D11208, doi:10.1029/2005JD006619d, 2006.

Dubovik, O. V., Lapyonok, T. V., and Oshchepkov, S. L.: Improved technique for data inversion: optical sizing of multicomponent aerosols, Appl. Opt., 34, 8422-8436, 1995.

Edie, W. T., Dryard, D., James, F. E., Roos, M., and Sadoulet, B.: Statistical Methods in Experimental Physics, North-Holland Publishing Company, Amsterdam, 155 pp., 1971.

EPA: Emissions of primary particulate matter and secondary particulate matter precursors, Assessment published December 2011, available at: http://www.epa.gov/ttn/chief/trends/, CSI 003, 2011.

Giles, D. M., Holben, B. N., Eck, T. F., Sinyuk, A., Smirnov, A., Slutsker, I., Dickerson, R. R., Thompson, A. M., and Schafer, J. S.: An analysis of AERONET aerosol absorption properties and classifications representative of aerosol source regions, J. Geophys. Res., 117, D17203, doi:10.1029/2012JD018127, 2012.

Guo, S., Hu, M., Guo, Q., Zhang, X., Schauer, J. J., and Zhang, R.: Quantitative evaluation of emission controls on primary and secondary organic aerosol sources during Beijing 2008 Olympics, Atmos. Chem. Phys., 13, 8303-8314, doi:10.5194/acp-13-83032013, 2013.

Hansen, J., Sato, M., and Ruedy, R.: Radiative forcing and climate response. J. Geophys. Res., 102, 6831-6864, 1997.

Hirsch, R. M. and Slack, J. R.: A Nonparametric Trend Test for Seasonal Data With Serial Dependence, Water Resour. Res., 20, 727-732, 1984. 
Hirsch, R. M., Slack, J. R., and Smith, R. A.: Techniques of trend analysis for monthly water quality data, Water Resour. Res., 18, 107-121, 1982.

Holben, B., Eck, T. F., Slutsker, I., Smirnov, A., Sinyuk, A., Schafer, J., Giles, D., and Dubovik, O.: Aeronet's Version 2.0 quality assurance criteria, Proc. SPIE, 6408(64080Q), doi:10.1117/12.706524, 2006.

Holben, B. N., Eck, T. F., Slutsker, I., Tanré, D., Buis, J. P., Setzer, A., Vermote, E., Reagan, J. A., Kaufman, Y. J., Nakajima, T., Lavenu, F., Jankowiak, I., and Smirnov, A.: AERONET-A federated instrument network and data archive for aerosol characterization, Remote Sens. Environ. 66, 1-16, 1998.

Hsu, N. C., Gautam, R., Sayer, A. M., Bettenhausen, C., Li, C., Jeong, M. J., Tsay, S.-C., and Holben, B. N.: Global and regional trends of aerosol optical depth over land and ocean using SeaWiFS measurements from 1997 to 2010, Atmos. Chem. Phys., 12, 8037-8053, doi:10.5194/acp-12-8037-2012, 2012.

Intergovernmental Panel on Climate Change (IPCC): Climate Change 2013: The Physical Science Basis, Contribution of Working Group I to the Fifth Assessment Report of the Intergovernmental Panel on Climate Change, Cambridge University Press, Cambridge, United Kingdom and New York, NY, USA, 2007.

Kendall, M. G.: Rank Correlation Methods, Griffin, London, 1975.

Kudo, R., Uchiyama, A., Yamazaki, A., Sakami, T., and Kobayashi, E.: From solar radiation measurements to optical properties: 1998-2008 trends in Japan, Geophys. Res. Lett., 37, L04805, doi:10.1029/2009GL041794, 2010.

Lu, Z., Zhang, Q., and Streets, D. G.: Sulfur dioxide and primary carbonaceous aerosol emissions in China and India, 1996-2010, Atmos. Chem. Phys., 11, 9839-9864, doi:10.5194/acp-11-98392011, 2011.

Lu, Z., Streets, D. G., de Foy, B., and Krotkov, N. A.: OMI Observations of Interannual Increase in $\mathrm{SO}_{2}$ Emissions from Indian Coal-Fired Power Plants during 2005-2012, Environ. Sci. Technol., 47, 13993-14000, 2013.

Lyapustin, A., Smirnov, A., Holben, B., Chin, M., Streets, D. G., Lu, Z., Kahn, R., Slutsker, I., Laszlo, I., Kondragunta, S., Tanré, D., Dubovik, O., Goloub, P., Chen, H.-B., Sinyuk, A., Wang, Y., and Korkin, S.: Reduction of aerosol absorption in Beijing since 2007 from MODIS and AERONET, Geophys. Res. Lett., 38, L10803, doi:10.1029/2011GL047306, 2011.

Mahowald, N. M., Ballantine, J. A., Feddema, J., and Ramankutty, N.: Global trends in visibility: implications for dust sources, Atmos. Chem. Phys., 7, 3309-3339, doi:10.5194/acp-7-3309-2007, 2007.

Mallik, C., Lal, S., Naja, M., Chand, D., Venkataramani, S., Joshi, $\mathrm{H}$., and Pant, P.: Enhanced $\mathrm{SO}_{2}$ concentrations observed over northern India: role of long-range transport, Int. J. Remote Sens., 34, 2749-2762, 2013.

Mann, H. B.: Nonparametric tests against trend, Econometrica , 13, 245-259, 1945

Mishchenko, M. I., Cairns, B., Kopp, G., Schueler, C. F., Fafaul, B. A., Hansen, J. E., Hooker, R. J., Itchkawich, T., Maring, H. B., and Travis, L. D.: Accurate monitoring of terrestrial aerosols and total solar irradiance: Introducing the Glory mission, B. Am. Meteorol. Soc., 88, 677-691, 2007.
Mishchenko, M. I., Liu, L., Geogdzhayev, I. V., Li, J., Carlson, B. E., Lacis, A. A., Cairns, B., and Travis, L. D.: Aerosol retrievals from channel-1 and -2 AVHRR radiances: Long-term trends updated and revisited, J. Quant. Spectrosc. Radiat. Transfer, 113, 1974-1980, 2012.

Murphy, D. M., Chow, J. C., Leibensperger, E. M., Malm, W. C., Pitchford, M., Schichtel, B. A., Watson, J. G., and White, W. H.: Decreases in elemental carbon and fine particle mass in the United States, Atmos. Chem. Phys., 11, 4679-4686, doi:10.5194/acp-11-4679-2011, 2011.

O'Neill, N. T., Ignatov, A., Holben, B. N., and Eck, T. F.: The lognormal distribution as a reference for reporting aerosol optical depth statistics; Empirical tests using multi-year, multisite AERONET Sunphotometer data, Geophys. Res. Lett., 27, 3333-3336, 2000.

Ramana, M. V., Ramanathan, V., Feng, Y., Yoon, S. C., Kim, S. W., Carmichael, G. R., and Schauer, J. J.: Warming influenced by the ratio of black carbon to sulphate and the black-carbon source, Nature Geosci., 3, 542-545, 2010.

Ramanathan, V., Crutzen, P. J., Kiehl, J. T., and Rosenfeld, D.: Aerosols, Climate, and the Hydrological Cycle, Science, 294, 2119-2124, 2001.

Russell, P. B., Bergstrom, R. W., Shinozuka, Y., Clarke, A. D., DeCarlo, P. F., Jimenez, J. L., Livingston, J. M., Redemann, J., Dubovik, O., and Strawa, A.: Absorption Ångström Exponent in AERONET and related data as an indicator of aerosol composition, Atmos. Chem. Phys., 10, 1155-1169, doi:10.5194/acp-101155-2010, 2010.

Sen, P. K.: Estimates of the regression coefficient based on Kendall's tau, J. Am. Stat. Assoc., 63, 1379-1389, 1968.

Stjern, C. W., Stohl, A., and Kristjansson, J. E.: Have aerosols affected trends in visibility and precipitation in Europe?, J. Geophys. Res., 116, D02212, doi:10.1029/2010JD014603, 2011.

Tarantola A., Inverse Problem Theory: Methods for Data Fitting and Model Parameter Estimation, Elsevier, Amsterdam, 500 pp., 1987.

Tørseth, K., Aas, W., Breivik, K., Fjæraa, A. M., Fiebig, M., Hjellbrekke, A. G., Lund Myhre, C., Solberg, S., and Yttri, K. E.: Introduction to the European Monitoring and Evaluation Programme (EMEP) and observed atmospheric composition change during 1972-2009, Atmos. Chem. Phys., 12, 5447-5481, doi:10.5194/acp-12-5447-2012, 2012.

von Storch, V. H.: Misuses of statistical analysis in climate research, in: Analysis of Climate Variability: Applications of Statistical Techniques, edited by: von Storch, H. and Navarra, A., SpringerVerlag, Berlin, 11-26, 1995.

Wang, K., Dickinson, R. E., and Liang, S.: Clear sky visibility has decreased over land globally from 1973 to 2007, Science, 323 , 1468-1470, 2009.

Weatherhead, E. C., Reinsel, G. C., Tiao, G. C., Meng, X.-L., Choi, D., Cheang, W.-K., Keller, T., DeLuisi, J., Wuebbles, D. J., Kerr, J. B., Miller, A. J., Oltmans, S. J., and Frederick, J. E.: Factors affecting the detection of trends: Statistical considerations and applications to environmental data, J. Geophys. Res., 103, 17149-17161, 1998.

Wild, M.: Global dimming and brightening: A review, J. Geophys. Res., 114, D00D16, doi:10.1029/2008JD011470, 2009.

Wild, M.: Enlightening global dimming and brightening, B. Am. Meteorol. Soc., 93, 27-37, 2012. 
Wild, M., Gilgen, H., Roesch, A., Ohmura, A., Long, C. N., Dutton, E. G., Forgan, B., Kallis, A., Russak, V., and Tsvetkov, A.: From dimming to brightening: Decadal changes in solar radiation at Earth's surface, Science, 308, 847-850, 2005.

Wild, M.: Global dimming and brightening: A review, J. Geophys. Res., 114, D00D16, doi:10.1029/2008JD011470, 2009

Xia, X. G.: Variability of aerosol optical depth and Ångström wavelength exponent derived from AERONET observations in recent decades, Environ. Res. Lett., 6, 044011, doi:10.1088/17489326/6/4/044011, 2011.

Yoon, J., von Hoyningen-Huene, W., Kokhanovsky, A. A., Vountas, M., and Burrows, J. P.: Trend analysis of aerosol optical thickness and Ångström exponent derived from the global AERONET spectral observations, Atmos. Meas. Tech., 5, 1271-1299, doi:10.5194/amt-5-1271-2012, 2012.

Yue, S., Pilon, P., Phinney, B., and Cavadias, G.: The influence of autocorrelation on the ability to detect trend in hydrological series, Hydrol. Process., 16, 1807-1829, 2002.
Zhang, J. and Reid, J. S.: A decadal regional and global trend analysis of the aerosol optical depth using a data-assimilation grade over-water MODIS and Level 2 MISR aerosol products, Atmos. Chem. Phys., 10, 10949-10963, doi:10.5194/acp-1010949-2010, 2010.

Zhang, X. and Zwiers, F. W.: Comment on "Applicability of prewhitening to eliminate the influence of serial correlation on the Mann-Kendall test" by Sheng Yue and Chun Yuan Wang, Water Resour. Res., 40, W03805, doi:10.1029/2003WR002073, 2004.

Zhang, X. Y., Wang, Y. Q., Lin, W. L., Zhang, Y. M., Zhang, X. C., Zhao, P., Yang, Y. Q., Wang, J. Z., Hou, Q., Che, H. Z., Guo, J. P., Li, Y., Gong, S., and Zhang, X. L.: Changes of Atmospheric composition and optical properties over Beijing 2008 Olympic monitoring campaign, B. Am. Meteorol. Soc., 90, 1633-1651, 2009. 